\title{
Slug flow as tool for selectivity control in the homogeneously catalysed solvent-free epoxidation of methyl oleate
}

\author{
Anoj Winston Gladius ${ }^{1}\left[\right.$ ] Johanna Vondran ${ }^{2} \cdot$ Yashwanth Ramesh $^{1} \cdot$ Thomas Seidensticker $^{2} \cdot$ David William Agar $^{1}$
}

Received: 21 December 2020 / Accepted: 24 August 2021 / Published online: 5 October 2021

(c) The Author(s) 2021

\begin{abstract}
Catalytic oxidation of sustainable raw materials like unsaturated fats and oils, or fatty acids and their esters, lead to biobased, high-value products. Starting from technical grade methyl oleate, hydrogen peroxide as a green oxidant produces only water as by-product. A commercially available, cheap water-soluble tungsten catalyst is combined with Aliquat ${ }^{\circledR} 336$ as a phasetransfer agent in solvent-free reaction conditions. In this study, we first report the transfer of this well-known batch system into continuous mode. The space-time yield is improved from $0.08 \mathrm{~kg} / \mathrm{L} . \mathrm{h}$ in batch to $1.29 \mathrm{~kg} / \mathrm{L} . \mathrm{h}$ in flow mode. The improved mass transfer and reduced back mixing of the biphasic liquid-liquid slug flow allows for selectivity control depending on physical parameters of slug flow namely volumetric phase ratio, volumetric flow rate, and slug length. Even though the product, methyl 9,10-epoxystearate is obtained at a maximum selectivity of only $58 \%$ in flow mode, higher space time yield combined with possible reactant recycling in flow mode offers a promising avenue of research. This work analyses the use of slug flow parameters as tools for controlling selectivity towards oxidation products of methyl oleate.
\end{abstract}

Keywords Phase transfer catalysis $\cdot$ Flow chemistry $\cdot$ Epoxidation $\cdot$ Peroxopolyoxotungstates $\cdot$ Slug flow

\section{List of Symbol}

$D$ “[m]"

$\Delta p$ "[bar]"

$\dot{\mathrm{V}}$ "[ $\left[\mathrm{ml} \mathrm{min} \mathrm{min}^{-1}\right]$ "

$\Delta H^{\prime \prime}\left[\mathrm{kJ} \mathrm{mol}{ }^{-1}\right] " \quad$ Enthalpy of reaction

$L$ "[mm]"

$F_{\text {org }} / F_{a q}$ " "[-]"

$R P M$ " $\left[\mathrm{min}^{-1}\right]$ "

$S$ "[-]"

$X$ “[-]"

$U F A$

$S F A$

FAME

$M O$
Diameter

Pressure difference

Volumetric flow rate

Segment length

Volumetric flow rate (organic/aqueous)

$\mathrm{H}_{2} \mathrm{O}_{2}$

TPA

$C$

PTC

$\mathrm{OA}$

ESAME

DSAME

Revolutions per minute

Selectivity

Conversion

Unsaturated fatty acid

Saturated fatty acid

Fatty acid methyl ester

Methyl oleate (Oleic acid methyl ester)

$M M A$

$C P C$

$P O M$
Anoj Winston Gladius

anoj.gladius@tu-dortmund.de

1 Laboratory for Chemical Reaction Engineering, Department of Biochemical and Chemical Engineering, TU Dortmund University, Emil-Figge-Straße 66, 44227 Dortmund, Germany

2 Laboratory for Industrial Chemistry, Department of Biochemical and Chemical Engineering, TU Dortmund University, Emil-Figge-Straße 66, 44227 Dortmund, Germany
Hydrogen peroxide

Tungstophosphoric acid

Catalyst

Phase transfer catalyst

Oleic acid

Methyl 9,10-epoxystearate

9, 10-Dihydroxystearic acid methyl ester

$P A \quad$ Pelargonic acid

$P R \quad$ Phase ratio

Aliquat ${ }^{\circledR} 336$

PPOM

$Q A S$

$D o E$

FCCC

$T$ "[ $\left.{ }^{0} \mathrm{C}\right] "$

TFR

$S V$ "[ $\left[\mathrm{mm} \mathrm{s}^{-1}\right]$ "

$S L$ "[mm]"

$U$ "[ $\left[\mathrm{mm} \mathrm{s}^{-1}\right]$ "

$\eta$ "[mPas]"

$D$ “[mm]"
Monomethyl azelate

Methyltrioctyl ammonium chloride

Cetylpyridinium chloride

Polyoxometalate

Peroxopolyoxometalate

Quaternary ammonium salts

Design of experiments

Face centred central composite design

Temperature

Total flow rate

Slug velocity

Slug length

Velocity

Dynamic viscosity

Diameter 


\begin{tabular}{|c|c|}
\hline$S G$ & Slug generator \\
\hline$C a$ "[-]" & Capillary number \\
\hline$h$ "[ $[\mu \mathrm{m}] "$ & Wall film thickness \\
\hline$R$ “[m]” & Radius \\
\hline$F S$ & Flow sensors \\
\hline$F E P$ & Fluorinated ethylene propylene \\
\hline PTFE & Polytetrafluoroethylene \\
\hline$P S$ & Pressure sensors \\
\hline
\end{tabular}

\section{Introduction}

In terms of Green chemistry, fats and oils can serve as highly attractive substrates for the sustainable chemical industry [1]. Through selective epoxidation of the internal double bond of unsaturated fatty acids or derivatives, bio-based epoxy compounds can be formed [2]. As an example, epoxidized soybean oil is applied as a plasticizer and stabilizer for poly(vinyl chloride) [3]. Additionally, ring-opening oligomerization and reduction to primary alcohols can be applied for the synthesis of renewable resource-based polyurethanes [4]. Furthermore, epoxides can be used for coatings, paints, or lubricants [5]. A very environmentally benign epoxidation method includes the application of hydrogen peroxide, air, or even pure oxygen as green oxidants [6]. Due to their low molecular weight and the therefore high relative amount of active oxygen, a lower environmental factor relating to Sheldon's definition of the mass of waste per mass of value product occurs [7] compared to toxic, inorganic oxidants such as $\mathrm{CrO}_{3}, \mathrm{KMnO}_{4}$ and $\mathrm{MnO}_{2}$ [8]. On the other hand, the use of oxygen-rich oxidants often results in exothermic side-reactions that are hard to control, especially on an industrial scale. The Prileshajev epoxidation with organic percarboxylic acids, formed from $\mathrm{H}_{2} \mathrm{O}_{2}$ and a carboxylic acid, is commonly used, although extremely acidic conditions are caused by the application of formic or acetic acid as oxygen transfer agents and strong inorganic acids as catalysts. Consequently, corrosion might be an issue, and neutralization and separation of the acid are required before subsequent conversion of the product. Therefore, epoxidation routes based on transition metals or enzymes are highly favourable $[9,10]$. The oxidant, hydrogen peroxide, is directly used without the formation of percarboxylic acids resulting in non-acidic, non-corrosive conditions. Generally, due to the low polarity of long-chained fatty acid methyl esters, epoxidation with aqueous hydrogen peroxide is challenging [11]. However, several transition metal catalysts based on e.g. Ru, Os, W, and others have been applied to epoxidation reactions of unsaturated fatty acids and their derivatives. Amongst them, tungsten is highly advantageous due to its cheaper price and lower toxicity. Especially tungsten polyoxometalates (POMs) such as Keggin-type heteropoly acid tungstophosphoric acid $\left(\mathrm{H}_{3} \mathrm{PW}_{12} \mathrm{O}_{40}, \mathrm{TPA}\right)$ have been in the focus of research, usually applied in a twophase system with a phase transfer agent (PTA) allowing for organic solvent-free reaction conditions as developed by Venturello [12]. Commonly used phase transfer agents are e.g. cetyl pyridinium chloride (CPC) and methyltrioctylammonium chloride (Aliquat ${ }^{\circledR}$ 336) [1]. Mechanistically, the oxygen atom is first transferred from hydrogen peroxide to the heteropolyanion. After the transfer of the peroxo POM through a PTA into the organic phase, the oxygen atom can be transferred to the substrate. The remaining POM is then regenerated by $\mathrm{H}_{2} \mathrm{O}_{2}$ at the interface [13] making mass transfer limited at the interface.

To improve mass transfer, the implementation of capillary microreactors can be considered. The small dimensions result in a high surface to volume ratio between the two liquids, causing external heat transfer and internal mass transfer. Moreover, superior reaction performances can be achieved in a continuous reactor that does not employ any mechanical moving parts to increase the contact between the biphasic medium.

The liquid-liquid slug flow is a two-phase flow regime that occurs in capillaries, offering several characteristics beneficial to the performance and controllability of twophase reaction systems. It is made up of two immiscible liquids where one liquid shows a higher affinity toward the capillary material. The high-affinity liquid forms a continuous phase in which the other liquid is present in the form of disperse slugs, separated from the capillary by a thin wall film as illustrated in Fig. 1 [14].
Fig. 1 Liquid-liquid slug flow with Taylor vortices [14]

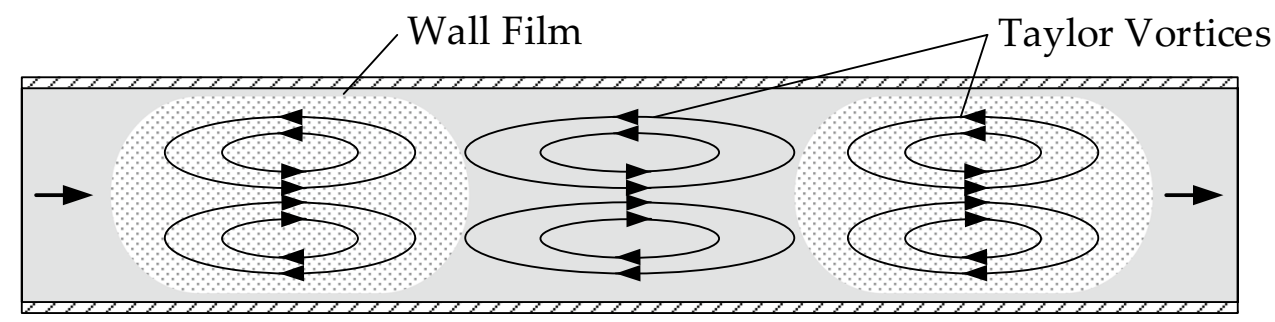

Disperse Phase
Continuous Phase 
The presence of the wall film has non-negligible effects on both pressure drop, as well as mass transfer between the two phases $[15,16]$. Its width $h$ in relation to the capillary radius $R_{C}$ may be calculated using the capillary number $\mathrm{Ca}$ of the continuous phase [17]:

$h=1.34 R_{C} C a^{2 / 3}$

$C a=\frac{\eta v_{s}}{\sigma}$

Another important characteristic of the liquid-liquid slug flow with importance toward mass transfer lies in the flow pattern within the slugs and inter-slug regions. Due to frictional forces and barriers posed by phase interfaces Taylor vortices may form. A quantitative analysis of the flow pattern withing liquid-liquid slug flows (using a paraffin-water model system) by Kashid et al. employs the dimensionless recirculation time $\tau$ as a measure of vortex intensity. [18]

$\tau=\frac{L_{s}\left(R^{2}-R_{0}^{2}\right)}{2 \frac{L_{s}}{v_{s}} \int_{R_{0}}^{R} U(r) r d r}$

Re-circulation time $\tau$ (describing the number of times a slug travels its own length until a typical fluid element has moved from one side of the slug to the other) thus depends upon the slug length $\mathrm{L}_{\mathrm{S}}$, slug velocity, radial velocity profile $U(r)$, radial position of the vortex boundary $R$ as well as the radial position of the vortex centre $\mathrm{R}_{0}$. Using particle tracing techniques as well as CFD modelling, the study finds that circulation times for both aqueous, as well as for organic phase lie between 3 and 4 for systems exhibiting a wall film, changing only slightly with slug flow velocity and slug length at the flow rates considered in this work [18]. This means the vortex circulation velocity rises proportionally with the total flow rate. The presence of Taylor vortices is an advantage of the slug flow regime, positively impacting mass transfer by facilitating the internal mixing of the phases without the need for intrusive agitators [15]. Overall volumetric mass transfer coefficients of $0.88-1.67 \mathrm{~s}^{-1}$ are reported for slug flows in capillaries with inner diameter $0.5-1 \mathrm{~mm}$, thus providing a favourable environment for two-phase reaction systems [14, 19]. Using the example of the nitration of aromatics in a slug flow reactor, Dummann et al. show that conversion and the formation of by-products can be influenced simply by altering the flow velocity [19]. Slug flows are further characterized by their slug length and phase ratio. The slug length is dependent on the geometry of the phase mixer (referred to as slug generator), while the phase ratio is dependent on the individual flow rates supplied to the slug generator [16, 20]. Due to the well-defined nature of the flow pattern, the slug length and phase ratios of slug flows are strongly related to the amount of available

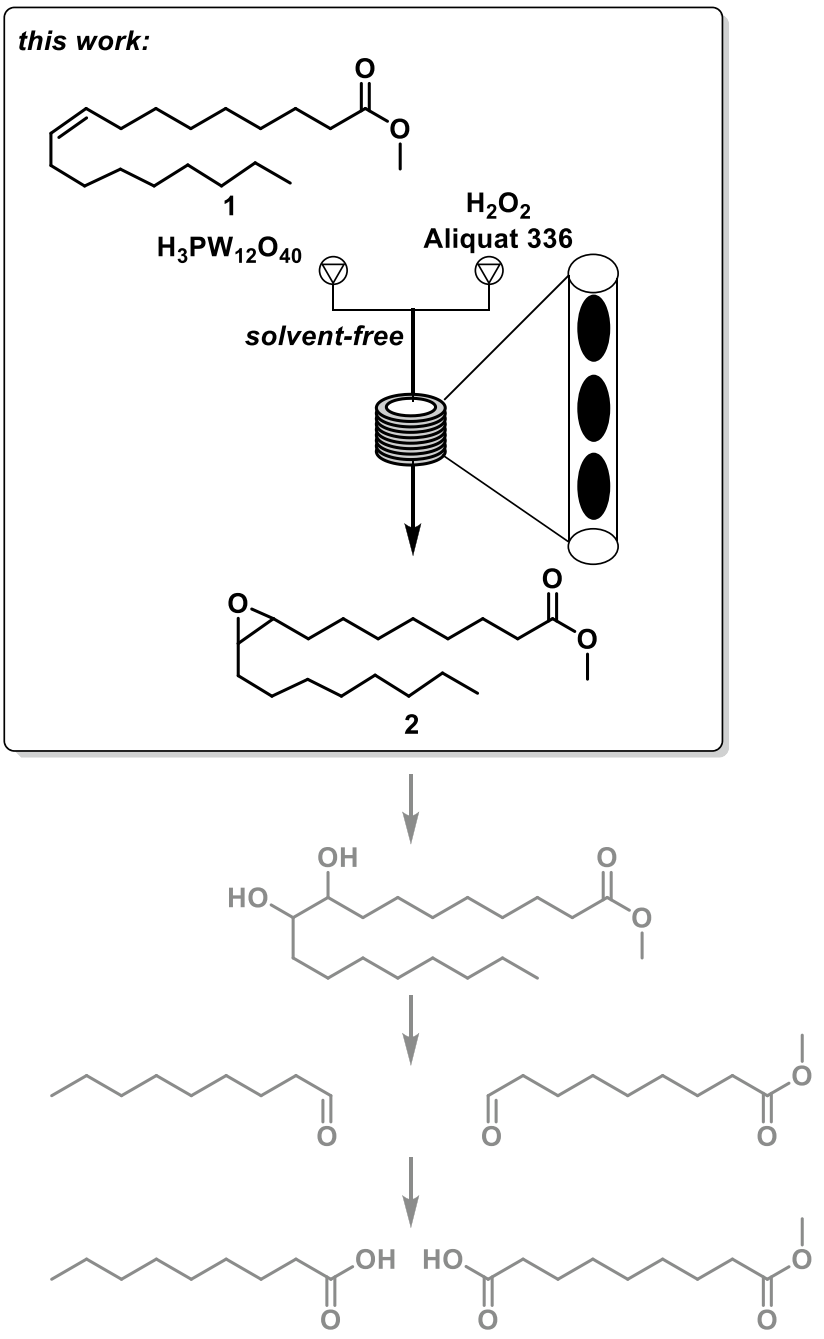

Fig. 2 Experimental set-up and potential subsequent reactions following epoxidation of methyl oleate

interfacial area [14]. By adjusting the slug length and the phase ratio, the performance of mass transfer limited twophase reactions may be further impacted.

In addition to mass transfer limitation in biphasic reaction media resulting in limited conversion, selectivity must be considered due to side- and subsequent reactions in terms of sustainable process development. Regarding the epoxidation of methyl oleate using the described catalyst system [20-22], full oxidative cleavage towards aldehydes or carboxylic acids is likewise feasible (Fig. 2) [23, 24]. Although the latter valuable bio-based products are obtained on an industrial scale [25] and exhibit various applications, selectivity must be controlled.

Considering the above-mentioned characteristics, slug flow reactors pose a promising basis for process intensification. Processes like two-phase reactions, which usually depend on active agitation, considerable residence times, and subsequent phase separation can be achieved with 
minimal moving parts (i.e. in-line phase mixing using the slug generator) and small volumes due to highly effective mass and heat transfer $[14,20]$. Furthermore, by including a continuous separation device based on wetting behaviour as demonstrated by Gaakeer et al. and Scheiff et al., the slugflow reactor could potentially deliver two separated process streams, achieving mixing, reaction and phase separation in a combined process $[21,22]$.

In the present work, the biphasic epoxidation of methyl oleate is transferred from batch to continuous liquid-liquid slug flow mode. TPA is solved in the aqueous hydrogen peroxide phase, whilst methyl oleate and the phase transfer agent form the organic phase. Special emphasis is on an improved mass transfer through control of physical parameters such as slug length, volumetric flow rate, and phase ratio which are also found to be tools to control selectivity.

\section{Batch Experiments \& Results}

These experiments are performed with technical grade MO (Inkemia Green Chemicals) containing 70\% MO by weight. The impurities consist of the saturated fatty acid methyl esters methyl palmitate and methyl stearate. $1.5 \mathrm{~g}$ ( $0.0035 \mathrm{~mol})$ of technical grade $\mathrm{MO}$ is used for every experiment and 35\% $\mathrm{H}_{2} \mathrm{O}_{2}$ (Carl Roth $\mathrm{GmbH}$ ) is chosen for the experiments as highly concentrated $\mathrm{H}_{2} \mathrm{O}_{2}$ is potentially risky. Aliquat ® 336 (Alfa Aesar) and Tungstophosphoric acid (Carl Roth $\mathrm{GmbH}$ ) constitute the remaining of the reaction mixture.

Batch experiments are performed for the epoxidation of MO with a phase transfer catalysed - catalytic system with $\mathrm{H}_{2} \mathrm{O}_{2}$ as the oxidant. Experiments are also performed on the epoxidation of methyl oleate with Tungstophosphoric acid (TPA) as the catalyst and Cetylpyridinium chloride (CPC) as the Phase Transfer Catalyst (PTC) to selectively produce methyl 9,10-epoxystearate. The low solubility of CPC in the reaction medium and the presence of solid after the reaction quenching makes CPC an undesirable candidate for continuous operations. Aliquat ${ }^{\circledR} 336$ is reasonably soluble in water making it a candidate for continuous mode operation. Batch experiments with Aliquat ${ }^{\circledR} 336$ as PTC are, hence, necessary, as these parameters from batch experiments are used as the basis for the continuous experiments. Further details pertaining the experimental procedure in batch mode can be found in Appendix A.

\section{Optimization of batch epoxidation of methyl oleate using Statistical design of experiments}

To achieve the high conversion of methyl oleate (MO) and selectivity of epoxide, the statistical design of experiments is employed. An experimental plan is created including the most relevant factors influencing the system, such as the molar ratio of oxidant to the substrate $\left(\mathrm{H}_{2} \mathrm{O}_{2} / \mathrm{MO}\right)$, the molar ratio of substrate to the catalyst $(\mathrm{MO} / \mathrm{C})$, the molar ratio of $\mathrm{PTC} / \mathrm{C}$, temperature, reaction duration and stirring speed $[23,24]$. A statistical evaluation provides numerous advantages over manual evaluation when each factor is varied from one experiment to the next. Hence, the experiments are designed with the help of Modde 10.1 (More details in Appendix B).

Pai, Tolstikov et al. reported that, at lower temperatures/ ambient temperatures, very low conversion of olefins and alcohols is achieved [24]. Godard, Caro et al. observed higher temperatures increasing the possibility of unwanted side reactions as well as the decomposition of $\mathrm{H}_{2} \mathrm{O}_{2}$ to water and oxygen [25]. Taking these effects into consideration the operating window of temperature is chosen as 50 to $80{ }^{\circ} \mathrm{C}$.

Khleibnikova, Pai et al. proved that TPA forms tetra nuclear peroxopolyoxotungstate complex with $\mathrm{H}_{2} \mathrm{O}_{2}$ [23, 26]. Increasing the amount of catalyst therefore increases the amount of tetranuclear peroxopolyoxotungstate complex, resulting in increased reaction rates. Simple screening experiments are carried out to determine the operating window for the variable $\mathrm{MO} / \mathrm{C}$ and is fixed from 50 to 200 . The deciding factor in the lower limit of MO/C is the solubility of TPA in the organic phase. Since $\mathrm{H}_{2} \mathrm{O}_{2}$ is a mild oxidant, no reaction is observed with this Catalyst/PTA combination with $\mathrm{MO} / \mathrm{C}$ greater than 200 , hence the upper limit.

Theoretically, one molar equivalent of $\mathrm{H}_{2} \mathrm{O}_{2}$ is sufficient for epoxidation of the double bond in $\mathrm{MO}$ to form methyl 9,10-epoxystearate. Four molar equivalents of $\mathrm{H}_{2} \mathrm{O}_{2}$ reacting with one molar equivalent of MO results in oxidative cleavage of MO. Godard, Caro et al. have reported the requirement of a higher $\mathrm{H}_{2} \mathrm{O}_{2} / \mathrm{MO}$ molar ratio for oxidative cleavage due to the increased decomposition of $\mathrm{H}_{2} \mathrm{O}_{2}$ at higher reaction temperatures [25]. Since the selectivity of the epoxide is being considered, the bounds for the molar ratio of $\mathrm{H}_{2} \mathrm{O}_{2} / \mathrm{MO}$ are chosen as $\{1,4\}$.

The organic and aqueous phases are immiscible, making the effect of stirring speed an important factor. At higher stirring speeds (more than 600 RPM), a decrease in the yield of the product is observed during the screening experiments. This could be attributed to the introduction of oxygen bubbles in the reaction medium, with these oxygen bubbles decreasing the contact between the substrate and oxidant in a sealed batch reactor. No significant conversion of MO occurred with stirring speeds lower than 100 . Therefore, the stirring speed is varied between 100 to 600 RPM.

Pai, Tolstikov et al. believe that the peroxo anion $\left\{\mathrm{PO}_{4}\right.$ $\left.\left[\mathrm{WO}\left(\mathrm{O}_{2}\right)_{2}\right]_{4}\right]^{3-}$ is the active ionic species that transfer the oxygen to the organic phase due to the formation of a coordinate complex with a PTC in their system [24]. The amount of catalyst and PTC could therefore be inferred to have a direct impact on the conversion of MO and the selectivity of 
products. The molar ratio of PTC/C varies between 1 and 6 . For ratios greater than 6 , the selectivity of the product and conversion of MO are adversely affected. This is attributed by Pai, Tolstikov et al. to the lipophilicity of the participating cationic species of PTCs in the effective/ineffective transfer of peroxo-anion [24].

Khleibnikova, Pai et al. carried out such reactions for times varying from $1-5 \mathrm{~h}$, and the same time frame is selected for these experiments [23]. The list of factors varied for the DoE is summarized in Table 1.

The conversion of MO and the selectivity of methyl 9,10-epoxystearate, are set as the optimisation variables. The minimum and maximum limit for the conversion is set at 50 and $100 \%$ respectively and for selectivity of epoxide as 30 and $100 \%$ respectively. The target value for this procedure is set as $90 \%$ and $70 \%$ respectively, based on the figures obtained in similar literature.

Karmoker, Hasan et al. have similar systems and reported good results using the RSM Optimisation technique (Response surface methodology-RSM) [27, 28]. The same is chosen as the objective for this optimisation. The number of experiments required for identifying optimal reaction parameters depends on the number of factors. The difference in the number of experiments between conventional design and an FCCC - designed model is shown in

Table 1 List of factors and their ranges for DoE

\begin{tabular}{ll}
\hline Factors & Limits \\
\hline Temperature $\left({ }^{\circ} \mathrm{C}\right)$ & $50-80$ \\
PTC/C (molar ratio) & $1-6$ \\
$\mathrm{MO} / \mathrm{C}$ (molar ratio) & $50-200$ \\
$\mathrm{H}_{2} \mathrm{O}_{2} / \mathrm{MO}$ (molar ratio) & $1-4$ \\
Stirrer speed (rpm) & $100-600$ \\
Time (hours) & $1-5$ \\
\hline
\end{tabular}

Table 11 (Appendix C). The experiments are performed, and all the results are shown in Table 12 in Appendix D. For the model created using FCCC - design, the effect of factors on the conversion of $\mathrm{MO}$, as determined by statistical analysis, is shown in Fig. 3. The green bars represent the effects of individual factors and interacting factors. The effects being positive or negatively affects the conversion, respectively. The error bars represent the magnitude of the effect by each factor, the variability of the data, and the uncertainty in a reported measurement graphically. If the error bar includes zero, the factor becomes insignificant.

Figure 3 shows that the molar ratios of PTC/C, $\mathrm{H}_{2} \mathrm{O}_{2}$ / $\mathrm{MO}$, stirrer speed, and reaction time have a positive linear influence on the conversion of MO. The negative quadratic influences should be neglected since the error bars include the zero line. The stirring speed has the largest influence on conversion. The stirring of the reaction system increases the contact between the organic and aqueous immiscible phases by increasing the surface area of contact due to the turbulence. The increase in turbulence results in increased surface area available for the reactants to interact with the oxidant/ peroxo-anion, resulting in higher conversion. Furthermore, the large impact of stirring speed on conversion implies that the overall reaction system is limited by mass transfer in the range of stirring speeds used in this work.

The higher molar ratio of $\mathrm{H}_{2} \mathrm{O}_{2} / \mathrm{MO}$ implies increased production of oxidants. High $\mathrm{PTC} / \mathrm{C}$ ratios result in increased transportation of active ionic species from the aqueous phase to the organic phase, thereby increasing the amount of active peroxoanion in the organic phase giving higher values of conversion. The molar ratio of $\mathrm{MO} / \mathrm{C}$ and temperature does not have any linear or quadratic influence on the conversion of MO. However, some combination of these factors does influence the system. For example, there is a strong positive interaction between $\mathrm{MO} / \mathrm{C}$ molar ratio
Fig. 3 Influence of the factors on the conversion of methyl oleate, where Temp - Temperature, PTC:C $-\mathrm{n}_{\mathrm{PTC}} / \mathrm{n}_{\mathrm{C}}$, MO:C $-\mathrm{n}_{\mathrm{MO}} / \mathrm{n}_{\mathrm{C}}, \mathrm{H}_{2} \mathrm{O}_{2}-\mathrm{n}_{\mathrm{H} 2 \mathrm{O} 2} / \mathrm{n}_{\mathrm{MO}} \&$ Sti - Stirrer speed

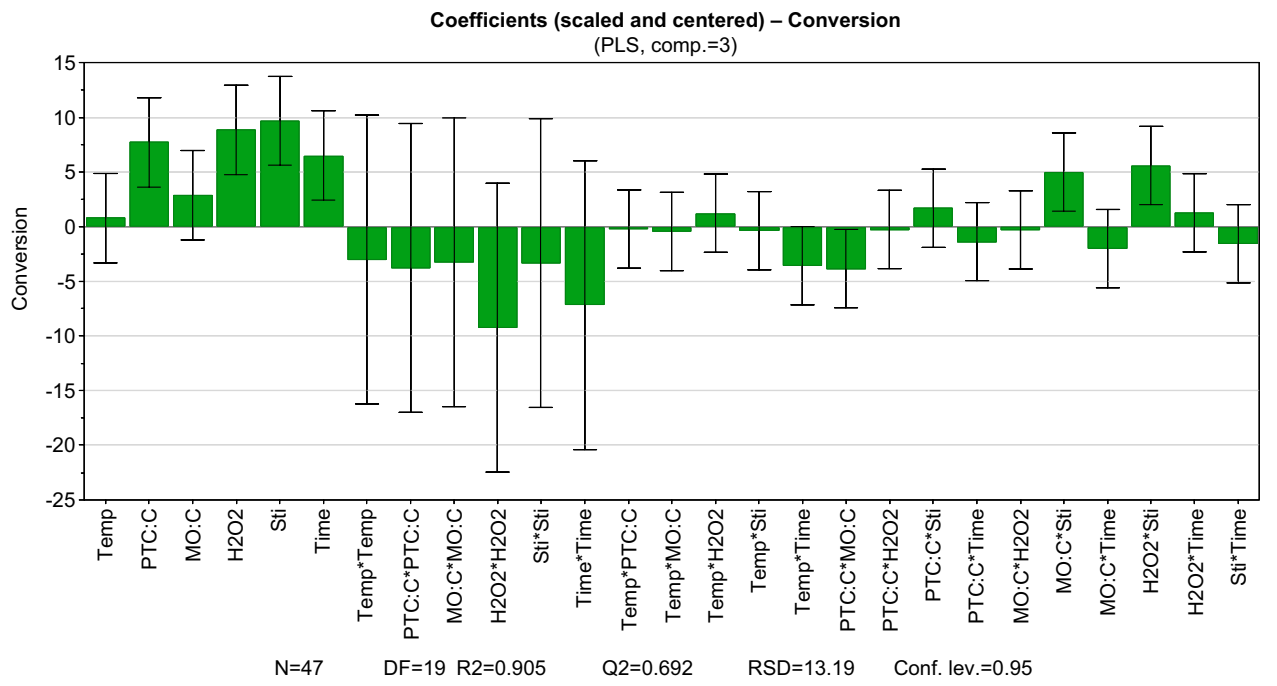


Fig. 4 Influence of the factors on the Selectivity of epoxide where Temp - Temperature, PTC: $\mathrm{C}-\mathrm{n}_{\mathrm{PTC}} / \mathrm{n}_{\mathrm{C}}, \mathrm{MO}: \mathrm{C}-\mathrm{n}_{\mathrm{MO}} /$ $\mathrm{n}_{\mathrm{C}}, \mathrm{H}_{2} \mathrm{O}_{2}-\mathrm{n}_{\mathrm{H} 2 \mathrm{O} 2} / \mathrm{n}_{\mathrm{MO}} \& \mathrm{Sti}-$ Stirrer speed

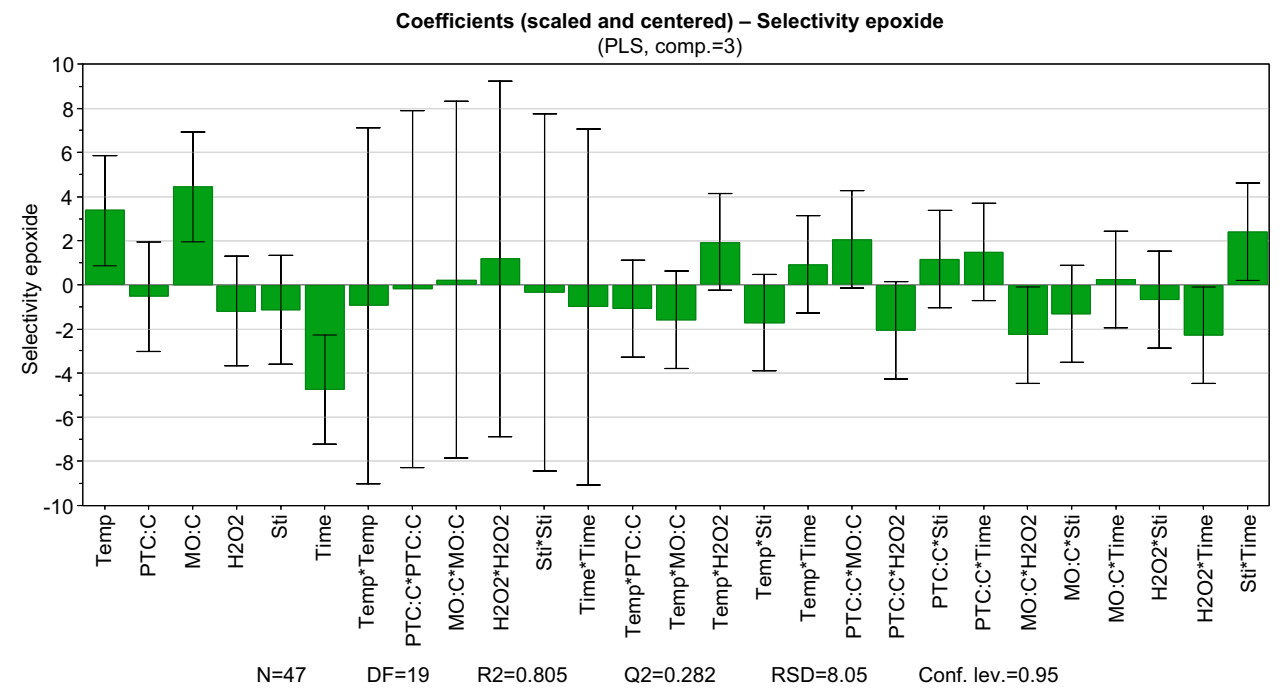

and stirrer speed as well as $\mathrm{H}_{2} \mathrm{O}_{2} / \mathrm{MO}$ molar ratio and stirrer speed and a negative interaction for $\mathrm{PTC} / \mathrm{C}$ and $\mathrm{MO} / \mathrm{C}$.

The effects of factors on the selectivity of epoxide are shown in Fig. 4. Contrary to what is shown in Fig. 3, the effect of temperature and the molar ratio of $\mathrm{MO} / \mathrm{C}$ has a positive linear influence on the selectivity of epoxide in comparison to conversion. The strong positive influence of $\mathrm{MO} / \mathrm{C}$ can be explained by the fact that the increase in $\mathrm{MO} / \mathrm{C}$ results in a decrease in the amount of catalyst in the reaction system. The lower amount of catalyst consequently reduces the amount of peroxo-anion formation, thereby reducing the further oxidation of MO into consecutive products resulting in the selective production of methyl 9,10-epoxystearate. Time has a strong negative linear influence on the selective production of the epoxide. With the increase in reaction time, the oxidation of MO can proceed to the next steps, resulting in lower yields of the epoxide.

Temperature notably influences the selective production of methyl 9,10-epoxystearate. Higher reaction medium temperatures lead to an increase in the decomposition of $\mathrm{H}_{2} \mathrm{O}_{2}$, leading to higher concentrations of oxygen radicles, which in turn lead to the formation of oxygen gas, limiting the number of oxidizing radicles available for oxidizing $\mathrm{MO}$ to further products. Although $\mathrm{H}_{2} \mathrm{O}_{2} / \mathrm{MO}$ does not have any linear significant impact on selective epoxidation, it should still be considered since it has a significant effect while combined with other factors. The interaction factor of $\mathrm{MO} / \mathrm{C}$ and $\mathrm{H}_{2} \mathrm{O}_{2} /$ $\mathrm{MO}$ also influences the reaction system. Without the linear effects, no quadratic and interacting effects are included in the model. Contour plots of both system responses (conversion and selectivity) are shown in Figures 20 and 21 in Appendix D.

The optimized reaction conditions are shown in Table 2 and the predicted conversion of MO and selectivity of methyl 9,10-epoxystearate at those conditions are shown
Table 2 Parameters optimized for Epoxidation in a Batch reactor

\begin{tabular}{ll}
\hline Factors & Optimal values \\
\hline H2O2/MO (molar ratio) & 1.13 \\
MO/C (molar ratio) & 194 \\
PTC/C (molar ratio) & 5.7 \\
Temperature & $60{ }^{\circ} \mathrm{C}$ \\
Stirrer speed & $500 \mathrm{rpm}$ \\
Duration of the reaction & $2.7 \mathrm{~h}$ \\
\hline
\end{tabular}

Table 3 Predicted results by the DoE vs Experimental results

\begin{tabular}{lll}
\hline & Predicted value & $\begin{array}{l}\text { Experi- } \\
\text { mental } \\
\text { value }\end{array}$ \\
\hline Conversion of MO & $80 \%$ & $73 \%$ \\
Selectivity of Epoxide & $55 \%$ & $52 \%$ \\
\hline
\end{tabular}

in Table 3. Table 3 shows that the experimentally obtained results are within a $10 \%$ margin of the predicted results. Figure 5 shows the deviation of all experimental results from the DoE-model (Coefficients listed in Tables 13 and 14 in Appendix D). The obtained values are in no way comparable to the results obtained by Kozhevnikov, Mulder et al. [11], reaching $95 \%$ conversion with $89 \%$ selectivity towards epoxide. However, the main objective of this work is not optimising conversion and selectivity in batch mode or for that matter in flow mode, but to determine the possibility of selectivity and product control in a flow reactor using slug flow parameters. Also, compared to Kozhevnikov, Mulder et al., this work employs relatively simple and cheap catalyst and PTC. The optimal parameters obtained in the batch mode are taken as the source for calculating the material 
Fig. 5 Deviation between observed results for conversion and selectivity toward epoxide and values predicted by the DoE model for a given set of influencing factors

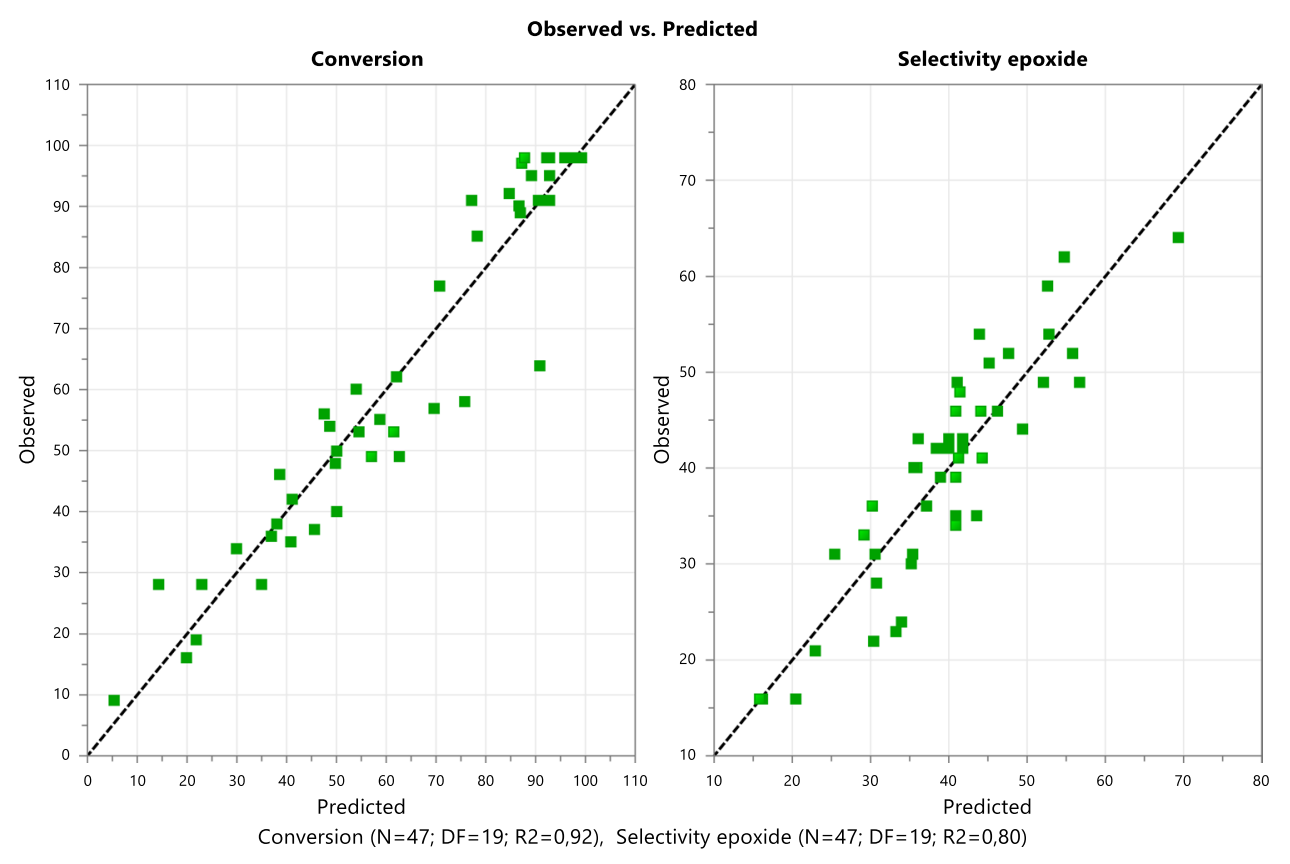

quantities necessary to perform epoxidation of MO in continuous flow mode.

\section{Flow Experiments \& Results}

A flow diagram of the experimental plant used in this work is shown in Fig. 6. The experimental slug flow reactor consists of a capillary made from fluorinated ethylene propylene (FEP) with a total length of $15 \mathrm{~m}$ and an inner diameter of one millimetre with three equidistanly spaced sampling ports located along the length of the reactor. Methyl oleate and PTC form the continuous phase while the disperse phase slugs are made up of the aqueous Hydrogen peroxide/TPA solution. Both phases are supplied using micro annular gear pumps (HNP microsystems GmbH, mzr-2921), and their flow rates are monitored by micro-scale flow sensors (Sensirion AG, Liquid Flow Meter SLI). The individual flow rates are controlled by pump rotations per minute (RPM).
Pressures of the supply channels as well as at the reactor outlet are measured by pressure transducers (Afriso-EuroIndex DMU-03).

Arsenjuk et al. and Vietinghoff et al. developed systems where the slug length at the reactor inlet is measured by an optical sensor shown in Fig. 7 consisting of a double infrared gate, where the passage of aqueous slugs through the infrared beam results in a reduction in measured beam intensity $[29,30]$. The slug flow is formed in the slug generator shown in Fig. 8-developed by Arsenjuk et al. - which features an adjustable geometry, allowing for the slug length in the slug flow reactor to be controlled [20]. The reactor is placed in a water bath heated to $60{ }^{\circ} \mathrm{C}$. Due to the small volume and high specific area of the capillary, isothermal reaction conditions may be assumed [19]. At the reactor outlet, a needle valve (Swagelok SS-SS1-A) is placed and connected to a stepper motor to control pressure.

Data is gathered from the sensors using an analogue data acquisition device (National Instruments NI-9205) and
Fig. 6 Process flow diagram of the experimental plant, indicating sensor-actuator pairs for plant control

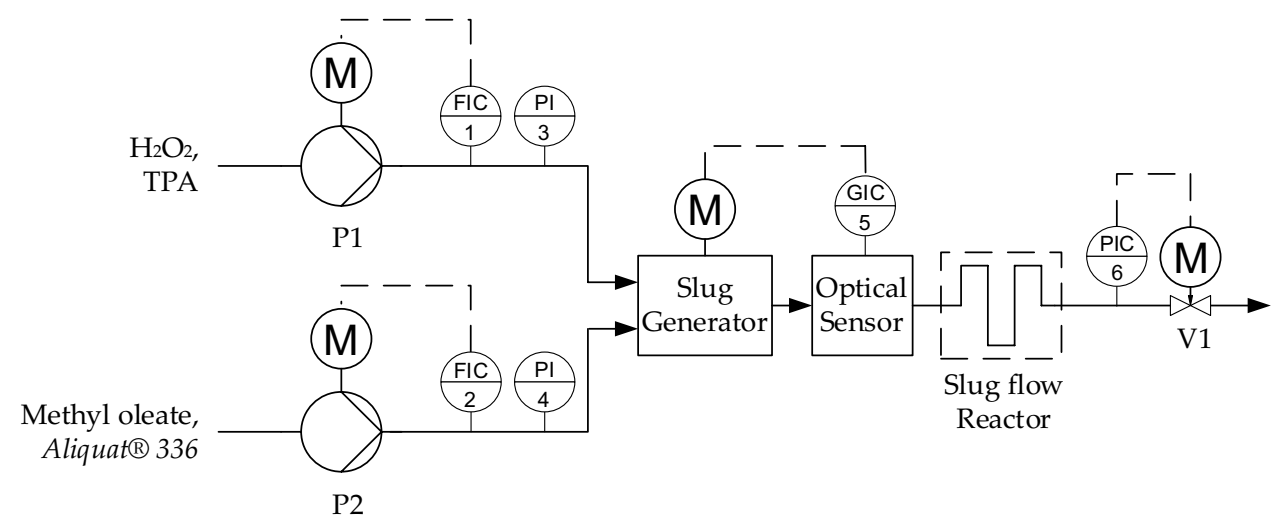




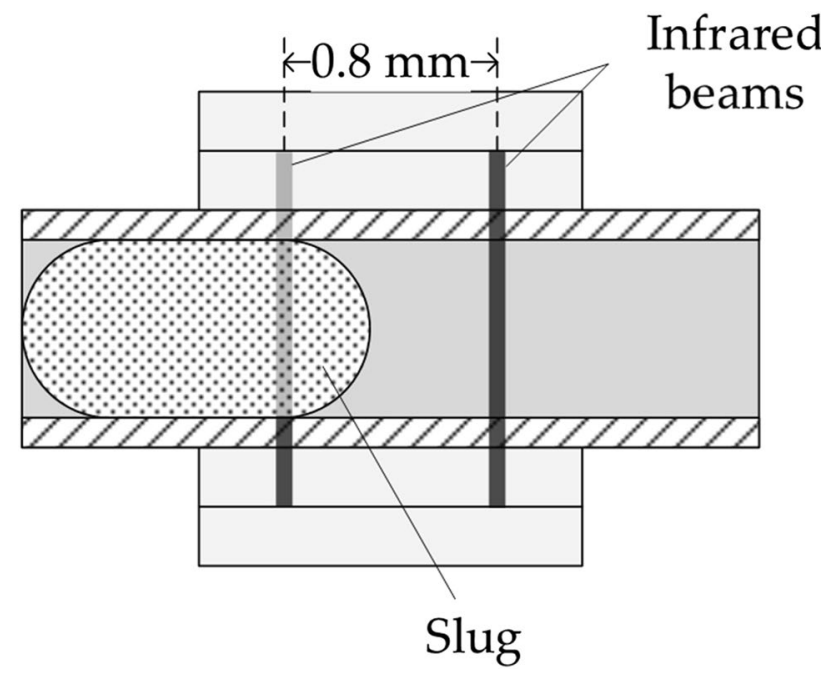

Fig. 7 Optical sensor [11, 29]

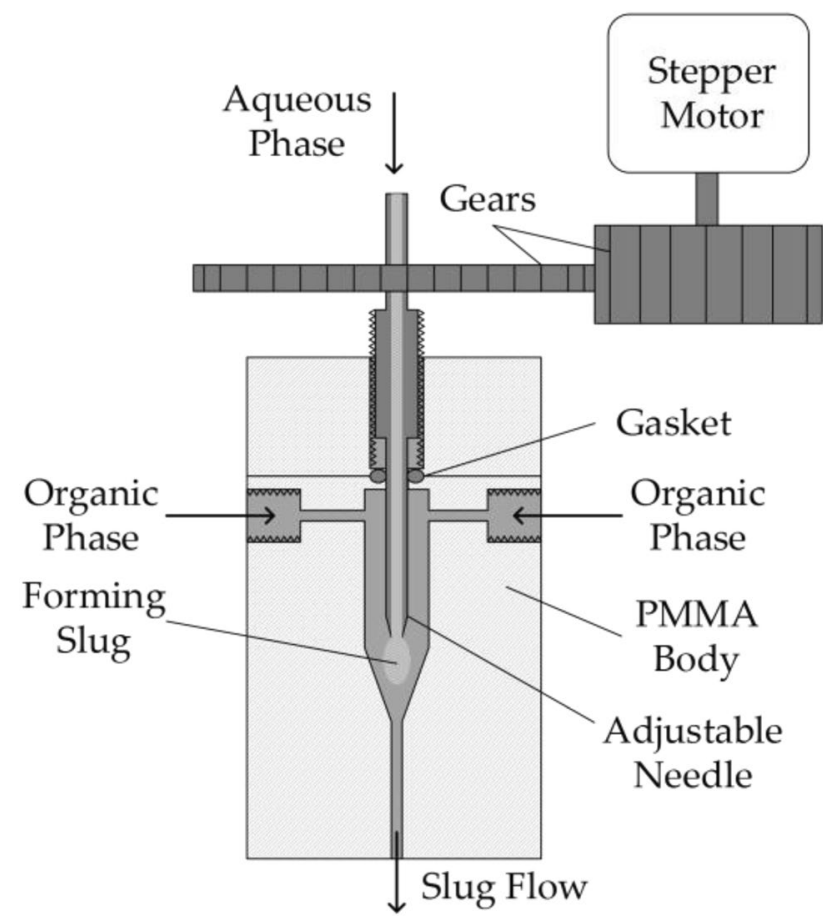

Fig. 8 Slug Generator [19]

processed using a program written in LabVIEW, a graphical programming environment executed on a computer. Control outputs to the pumps are issued by an analogue data output device (National Instruments NI-9264) while the stepper motors positioning slug generator and needle valve are controlled by a driver board (Trinamic TMCM-610) which receive instructions from the computer. This automated setup with a continuous flow microcapillary reactor allows the impact study of these parameters on reaction conversion and selectivity.

Gemoets, Su et al. state that the overall performance of an oxidation reaction is mainly determined by intrinsic kinetics and transport properties inside the reactor. They also make a case that for a fast liquid-phase oxidation reaction, the reaction rate and selectivity are influenced by the mass transfer rate and internal circulations within the slugs along with reaction kinetics [30]. The individual effects of the setpoints, i.e., volumetric flow rate, phase ratio, and the length of the slugs, on the solvent-free Aliquat ${ }^{\circledR} 336$ assisted oxidation of $\mathrm{MO}$ are discussed in the following sections.

In the transition of parameters from batch operation to continuous operation, some of the terms must be adapted for their usage. This transition is explained briefly in the Appendix E. The chemicals used in the flow experiments are the same as the ones used in batch mode. The calculated space-time yield for the best yield of epoxide in Batch mode is $0.08 \mathrm{~kg} / \mathrm{L} . \mathrm{h}$, whereas the best yields seen generally in flow reactors are usually in the range of $1-10 \mathrm{~kg} / \mathrm{L} . \mathrm{h}$. The following results also demonstrate similar trends. The best space-time yields achieved in flow mode is $4.49 \mathrm{~kg} / \mathrm{L} . \mathrm{h}$. The increased space-time yield for this reaction system is one clear reason to explore this reaction in the flow mode. Effects of various parameters in flow mode and the ability to control the reaction parameters are also studied in the following sections.

\section{Flow Results-Effect of length of flow reactor}

Flow results are represented along the length of the reactor. Results show that the conversion of MO always increases with the length of the reactor and in some cases plateaus after a certain amount of time spent in the reactor. This is true for most irreversible reaction systems. Due to the presence of various possible subsequent reaction paths, the general trend for the selectivity of MO towards epoxide is to decrease along the length of the reactor. However, both in the case of conversion and selectivity, the slopes of the curves have been proven to be controllable by controlling the respective slug flow variables.

Residence times, volumetric flow rates, and reactor length may at first glance seem like a set of redundant variables. However, that is not the case. Fixing a certain residence time by manipulating the reactor length and volumetric flow rate may theoretically constitute the same system. For example, a residence time of $10 \mathrm{~min}$ in a capillary microreactor could be achieved in any number of ways, 2 of which being, a reactor length of $10 \mathrm{~m}$ and a flow velocity (derived from volumetric flow rate) of $1 \mathrm{~m} / \mathrm{min}$ and a reactor length of $20 \mathrm{~m}$ and a flow velocity of $2 \mathrm{~m} / \mathrm{min}$. However, recalling the dependence of recirculation time on slug velocity it is seen that the mixing characteristics of the system, like the stirring speed of 


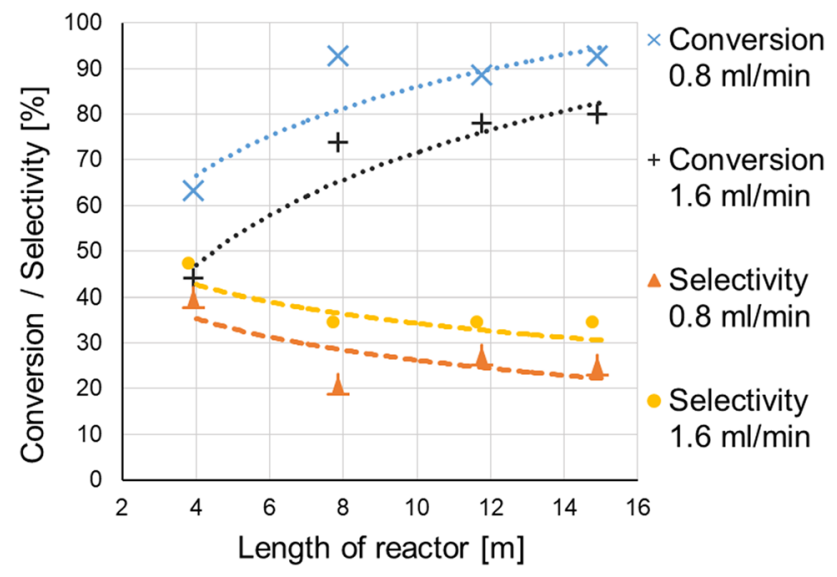

Fig. 9 Length vs Conversion \& Selectivity plot with trend for variation in volumetric flowrate. Phase ratio $-3\left(\mathrm{~F}_{\mathrm{org}} / \mathrm{F}_{\mathrm{ag}}\right)$; Slug length - $2 \mathrm{~mm}$; Total Volumetric flowrate a) $0.8 \mathrm{ml} / \mathrm{min}$ [organic phase - $0.6 \mathrm{ml} / \mathrm{min}$; aqueous phase $-0.2 \mathrm{ml} / \mathrm{min}$ ] b) $1.6 \mathrm{ml} / \mathrm{min}$ [organic phase $-1.2 \mathrm{ml} / \mathrm{min}$; aqueous phase $-0.4 \mathrm{ml} / \mathrm{min}$ ]

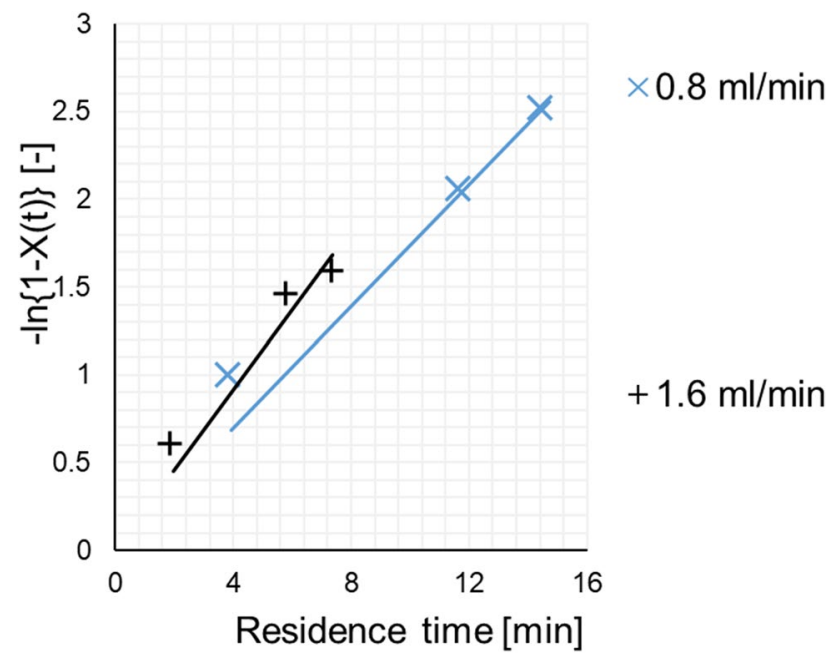

Fig. 10 Rearranged rate law vs residence time with line fit, Phase Ratio -3 , Slug length $-2 \mathrm{~mm}$, for different total flow rates

a batch reactor, is another control variable that affects the system in a non-trivial way $[16,18]$. Thus, these variables are treated independently in this work and their individual effects are studied in a more detailed fashion.

Using the same catalytic system consisting of TPA and Aliquat $336 \AA$ as used in this work, Wang et al. find that a simplified first-order kinetic model is sufficient to describe the epoxidation of 1,7-Octadiene with $\mathrm{H} 2 \mathrm{O} 2$. Therein the complex of peroxo-anion $\left\{\mathrm{PO}_{4}\left[\mathrm{WO}\left(\mathrm{O}_{2}\right)_{2}\right]_{4}\right\}^{3-}$ and quaternary ammonium salt Aliquat $336 \AA$ is assumed to be the active species. Assuming the concentration of active species $\mathrm{c}_{\text {cat }}$ in the organic phase is at pseudo-steady-state and that the reoxidation of the active species takes place in a boundary layer at the phase transition, they derive for the first epoxidation step of reactant $\mathrm{A}$ (with concentration $\mathrm{c}_{\mathrm{A}}$ ) in the organic phase: [31]

$\frac{d c_{A}}{d t}=-k c_{c a t} c_{A}=-k_{a p p} c_{A}$

where $\mathrm{k}$ is the intrinsic rate constant of the reaction and $\mathrm{k}_{\text {app }}$ the apparent rate constant. Integrating and adapting the above Eq. (4) to the system at hand yields:

$1-\frac{c_{M O}}{c_{M O, 0}}=X_{M O}(\mathrm{t})=1-\exp \left(-k_{a p p} t\right)$

The rate of reaction thus depends upon the (unknown) local concentration of the active catalyst species, which in turn depends on influencing factors, such as the goodness of mixing. In a subsequent publication, Wang et al. proceed to assess the influence of reaction conditions (stirring speed, reactant concentrations, etc.) on the overall reaction performance using the apparent rate constant. Therefore, in this work an apparent rate constant $\mathrm{k}_{\mathrm{app}}$ is determined for different settings of the slug flow reactor and employed as a relative measure of reactor performance. Because only few points are available, the apparent rate constant is approximated by the slope-of-the-line method using the rearranged rate law (6) and linear regression of the data points. [31, 32]

$-\ln \left\{1-X_{M O}(\mathrm{t})\right\}=k_{\text {app }} t$

\section{Flow Results-Effect of Volumetric flowrate}

Six Experiments are conducted to determine the effect of varying volumetric flow rates on the oxidation of MO. Two flow rates $(0.8 \mathrm{ml} / \mathrm{min}$ and $1.6 \mathrm{ml} / \mathrm{min})$ are analysed with two constant slug length and phase ratio combinations (PR 3 \& SL $2 \mathrm{~mm}$, PR $7 \&$ SL $8 \mathrm{~mm}$ ). The high conversions (greater than 95\%) reached at longer reactor lengths (15 m) in almost all cases are to be noted. Since the work is done with microcapillaries, the effective reactor volume is also small $(11.5 \mathrm{ml})$. This along with low residence times of 2 to $14.7 \mathrm{~min}$, results in high space-time yields for epoxide in flow mode $(4.49 \mathrm{~kg} / \mathrm{L} \mathrm{h})$. Considering a measured power consumption of the stirrer of $3.8 \mathrm{~W}$ and a measured power consumption of the micro gear pumps of $5.9 \mathrm{~W}$ (combined), one mole of desired product (epoxide) under best observed reaction conditions requires $420.5 \mathrm{~kJ} / \mathrm{mol}$ of mechanical energy in the slug flow reactor and $20,310.4 \mathrm{~kJ} / \mathrm{mol}$ of mechanical energy in batch mode. Much of this is likely attributable to mechanical losses. Nonetheless, the mechanical power required by the slug flow reactor is substantially lower.

Naturally, because of the difference in residence time, the higher the volumetric flow rate the longer a reactor is 
Table 4 Apparent rate constants of MO epoxidation determined from Fig. 10 and average observed selectivity for different total flow rates. Phase ratio 3, slug length $2 \mathrm{~mm}$

\begin{tabular}{lll}
\hline $\begin{array}{l}\text { Total Flow Rate in } \mathrm{ml} \\
\mathrm{min}^{-1}\end{array}$ & $\mathrm{k}_{\mathrm{app}}$ in $\mathrm{min}^{-1}$ & $\begin{array}{l}\text { Average Selec- } \\
\text { tivity Epoxide } \\
\text { in \% }\end{array}$ \\
\hline 0.8 & 0.174 & 27.6 \\
1.6 & 0.229 & 35.6 \\
\hline
\end{tabular}

required to achieve the same conversion levels. For example, in Fig. 9, for a phase ratio of $3(\mathrm{Forg} / \mathrm{Faq}=3)$ and slug length of $2 \mathrm{~mm}$, the total volumetric flow rates are varied between $0.8 \mathrm{ml} /$ $\min$ and $1.6 \mathrm{ml} / \mathrm{min}$, leading to differing final conversions. In addition, the reactor length vs conversion curve shows that, at a total volumetric flow rate of $1.6 \mathrm{ml} / \mathrm{min}$, the length of the reactor to achieve a conversion of $70 \%$ is $\sim 8 \mathrm{~m}$, whereas for a length of $4 \mathrm{~m}$ (i.e. constant residence time) $62 \%$ conversion of $\mathrm{MO}$ is achieved for a flow rate of $0.8 \mathrm{ml} / \mathrm{min}$, indicating a faster progression of the reaction. This is further shown by Fig. 10 and the apparent reaction rate constants in Table 4. The reaction converting MO is slightly faster for a higher flow rate. This can likely be attributed to more intense mixing as the vortex intensity increases with slug velocity, which is proportional to the total flow rate.

In, the average selectivity of epoxide is $35.6 \%$ for a volumetric flow rate of $1.6 \mathrm{ml} / \mathrm{min}$ whereas the average selectivity is $27.6 \%$ for a volumetric flow rate of $0.8 \mathrm{ml} / \mathrm{min}$. In this case, the flow rate has no discernible impact on the selectivity as both trend curves show roughly the same slope. The difference in average selectivity is likely due to the longer residence time. As MO depletes along the reactor, epoxide is converted to subsequent products while the production of epoxide slows.

As shown in Fig. 11, for a phase ratio of 7 and slug length of $2 \mathrm{~mm}$, conversions for a $0.8 \mathrm{ml} / \mathrm{min}$ flow rate range from

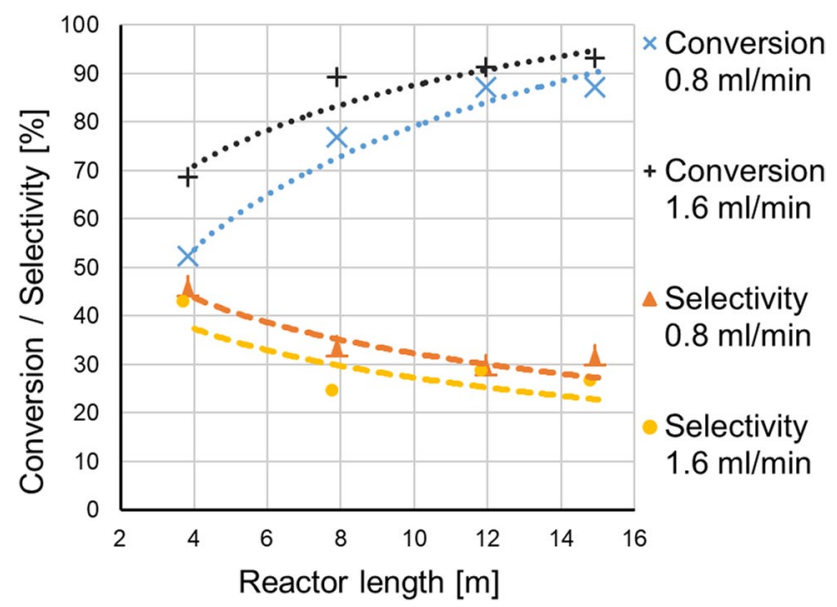

Fig. 11 Length vs Conversion \& Selectivity plot with trend for variation in volumetric flowrate. Phase ratio - 7 (Forg/ Faq); Slug length $-2 \mathrm{~mm}$; Total Volumetric flowrate a) $-0,8 \mathrm{ml} / \mathrm{min}$ [organic phase - 0,7 $\mathrm{ml} / \mathrm{min}$; aqueous phase $-0,1 \mathrm{ml} / \mathrm{min}$ ] b) $1,6 \mathrm{ml} / \mathrm{min}$ [organic phase $-1,4 \mathrm{ml} / \mathrm{min}$; aqueous phase $-0,2 \mathrm{ml} / \mathrm{min}$ ]

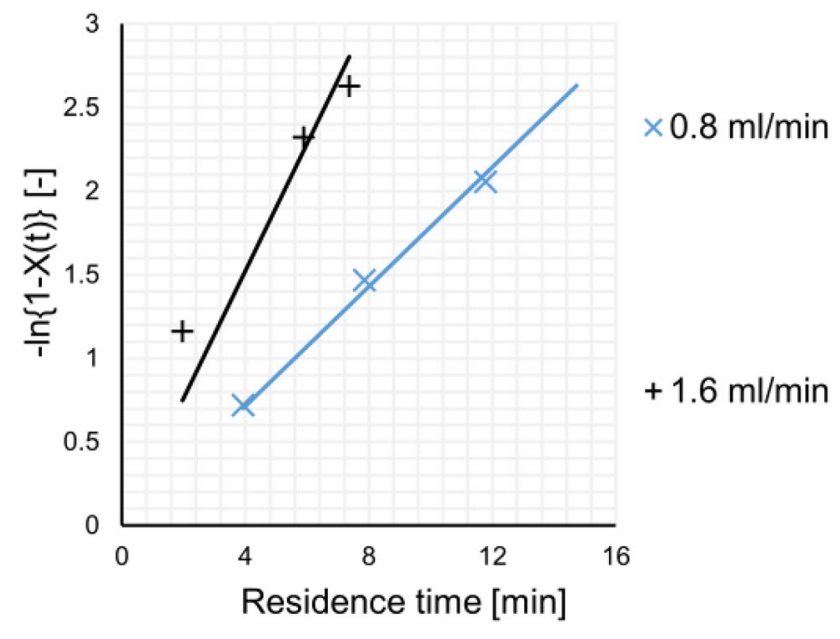

Fig. 12 Rearranged rate law vs residence time with line fit, Phase Ratio -7 , Slug length $-2 \mathrm{~mm}$, for different total flow rates

$50 \%$ at $4 \mathrm{~m}$ to $87 \%$ at $15 \mathrm{~m}$ of reactor length. The same for $1.6 \mathrm{ml} / \mathrm{min}$ range from 70 to $92 \%$, showing similar trends as in the previous cases, however the reaction is over twice as fast for the higher flow rate in this case, marking a much greater increase (Fig. 12 and Table 5). The selectivity of epoxide is similar in this case for both the flowrates for most of the reactor length, with the selectivity for the higher flow rate being slightly slower. This could be attributed to the increased concentration of epoxide as well as to factors discussed in the section explaining the effect of phase ratio and slug length.

The contradicting forces at play can be seen as a means of controlling the reaction outcome within the context of the automated slug-flow control setup. It is shown that the same system with the same concentration of reactants can be manipulated physically, by controlling the slug flow parameters, to react differently enabling the possibility to exert a high degree of control on the system.

\section{Effect of change in Phase Ratio \& Slug length}

Shown below in Fig. 13 are 4 cases of varying slug lengths and phase ratios, wherein only one variable is changed from one case to another. The effect of slug length and phase ratio is explained as the result of three competing forces

Table 5 Apparent rate constants of MO epoxidation determined from Fig. 12 and average observed selectivity for different total flow rates. Phase ratio 7, slug length $2 \mathrm{~mm}$

\begin{tabular}{lll}
\hline $\begin{array}{l}\text { Total Flow Rate in } \mathrm{ml} \\
\min ^{-1}\end{array}$ & $\mathrm{k}_{\mathrm{app}}$ in $\mathrm{min}^{-1}$ & $\begin{array}{l}\text { Average Selec- } \\
\text { tivity Epoxide } \\
\text { in \% }\end{array}$ \\
\hline 0.8 & 0.179 & 34.0 \\
1.6 & 0.381 & 28.8 \\
\hline
\end{tabular}


Fig. 13 Illustration of the effect of slug length and phase ratio variation on slug flow geometry

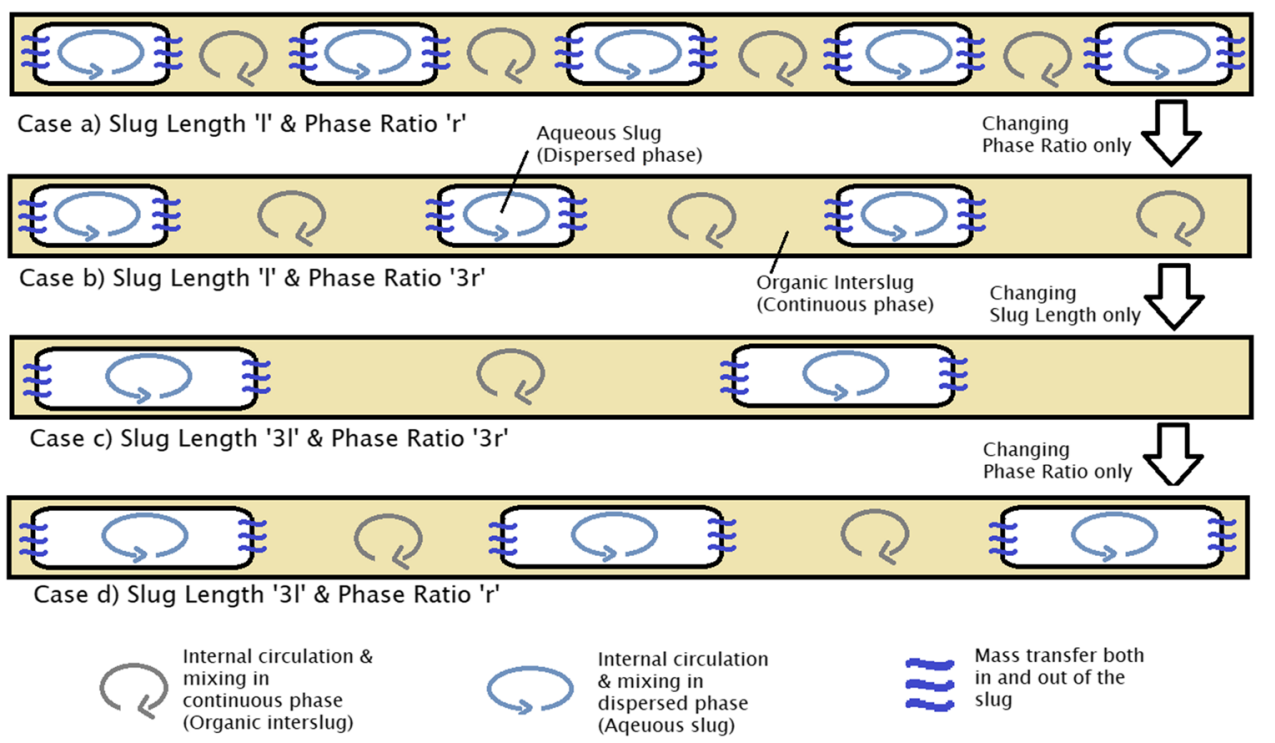

as highlighted in Fig. 13, where various instances of a unit length microcapillary reactor are shown. An analogy to a batch reactor is drawn to clarify what is happening in this system.

Phase ratio being constant across a unit length of a microreactor is assumed to be equivalent to a fixed reactant concentration system in batch and a phase ratio change is analogous to changing the molar concentration in a batch reactor. Batch mode experiments with a fixed concentration of the reactants and different stirrer speeds are assumed to be analogous to case a) and case d) in Fig. 13. Similarly case b) and case c) also have the same concentration of reactants (phase ratio), but different interfacial areas.

Contrary to a batch reactor, where stirrer speed is the only control variable to affect physical mixing, in the flow mode, both volumetric flow rate (stirrer speed) as well as slug length (interfacial area) can be controlled. Temperature and other physical parameters do have a small effect on mixing, albeit these other effects affect both modes similarly. This extended degree of control allows this microcapillary system to not only have the advantages of a general flow reactor (reduced residence times \& continuity in the system), rather also the ability to extract different conversions and selectivities with a fixed reactant concentration upstream the pumps.

Given the definition of the phase ratio PR according to formula (7), the volume-specific interfacial area available for mass transfer inside the slug flow reactor is proportional to the sum of the areas of all slugs $\mathrm{A}_{\text {Slug,tot, }}$ which may be calculated from the volume of the reactor $\mathrm{V}_{\text {Reactor }}$ and the inner diameter of the reactor $\mathrm{D}_{\text {Reactor }}$ using formula (8). Assuming the width of the wall film $h$ is very small compared to the capillary diameter and the side of the slugs do not offer surface area for mass transfer, formula (8) may be simplified to yield formula (9). Using the simplified formula it can be estimated that the specific area available for mass transfer lies between $36-250 \mathrm{~m}^{2} / \mathrm{m}^{3}$, depending on slug length and phase ratio setting. If the side walls of the slugs take part in mass transfer the specific area increases by an order of magnitude, potentially improving mass transfer, but greatly reducing the relative impact of the slug length and phase ratio settings.

$P R=\frac{\dot{V}_{\text {org }}}{\dot{V}_{a q}}$

$A_{\text {Slug,tot }}=\frac{V_{\text {Reactor }} \frac{\pi}{2}\left[\left(D_{\text {Reactor }}-2 h\right)^{2}+2\left(D_{\text {Reactor }}-2 h\right) L_{s}\right]}{(1+P R) \frac{\pi}{4}\left(D_{\text {Reactor }}-2 h\right)^{2} L_{s}}$

$A_{\text {Slug,tot }} \approx \frac{2 V_{\text {Reactor }}}{(1+P R) L_{s}}$

For the sake of this particular explanation, volumetric flow is assumed to be constant across all cases. In the case of fixed phase ratio and increasing slug lengths, Case a) and d), as shown in Fig. 13, the amount of internal circulation in both the organic and the aqueous slugs decrease [16]. While the effect is comparatively small, according to Kashid et al., its presence and effect in mass transfer should not be neglected [18]. More importantly, the change in slug length means a change in the interfacial area $\mathrm{A}_{\text {Slug,tot }}$ according to Eq. (8). Overall, changes in slug length have several effects which may interplay, as convective transport within the slugs and interslug regions aids in reducing product accumulation at the interfaces while also facilitating transport of the active species to complete the catalytic cycle.

A way to exert a degree of control over the relative change in surface area is to use phase ratio as a control variable. 
Considering the pairs, Case a) \& b) and Case c) \& d), where the slug lengths remain constant whilst the phase ratios change, it is clear that the internal circulation in the aqueous slug remains constant while the internal circulation in the organic interslug changes because of the increased volume. This, again, affects the local concentration of species reactants/products available for the reaction within the interslug regions. In the interslug regions in particular, more intense circulation may aid in the dilution of epoxide at the interface, preventing further reaction toward the diol product, thus improving selectivity. Because in this study an excess of hydrogen peroxide is present in all cases, the change in phase ratio is assumed to not affect the maximum attainable conversion. In Sect. 3.3.1 \& 3.3.2, the effects of slug length and phase ratios are discussed from the results obtained in the respective flow experiments.

\section{Effect of change in Slug length}

Wada, Schmidt et al. [33] reported that the change in the size of the disperse phase slug affects the size of the continuous phase inter-slugs, i.e., phase ratio, in the context of Ozonolysis in a gas-liquid multichannel microreactor. However, in this work, owing to the design of the slug generator, the length of the aqueous slug is altered without having any effects on the phase ratio. Several experiments are hence conducted to understand the effect of change in slug lengths for a constant phase ratio since the effect of this characteristic has not been reported often before in literature.

Experiments are performed at different slug lengths (long and short slug lengths $-2 \mathrm{~mm}$ and $8 \mathrm{~mm}$ ) and the results are recorded and discussed. The volumetric phase ratio and total volumetric flow rate are maintained at a constant value. Figure 14 shows the conversion/selectivity vs length plot for a reaction system with phase ratio 3 , the volumetric flow

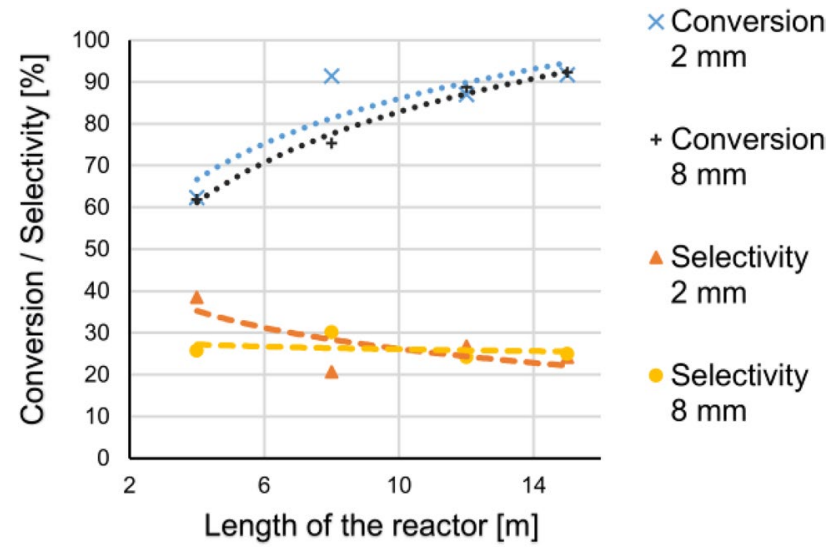

Fig. 14 Length vs Conversion \& Selectivity plot with trend for variation in slug length. Phase ratio $-3\left(\mathrm{~F}_{\mathrm{org}} / \mathrm{F}_{\mathrm{aq}}\right)$; Total Volumetric flowrate $-0,8 \mathrm{ml} / \mathrm{min}$ [organic- $0,6 \mathrm{ml} / \mathrm{min}$; aqueous $-0,2 \mathrm{ml} / \mathrm{min}$ ]; Slug length a) $2 \mathrm{~mm}$; b) $8 \mathrm{~mm}$

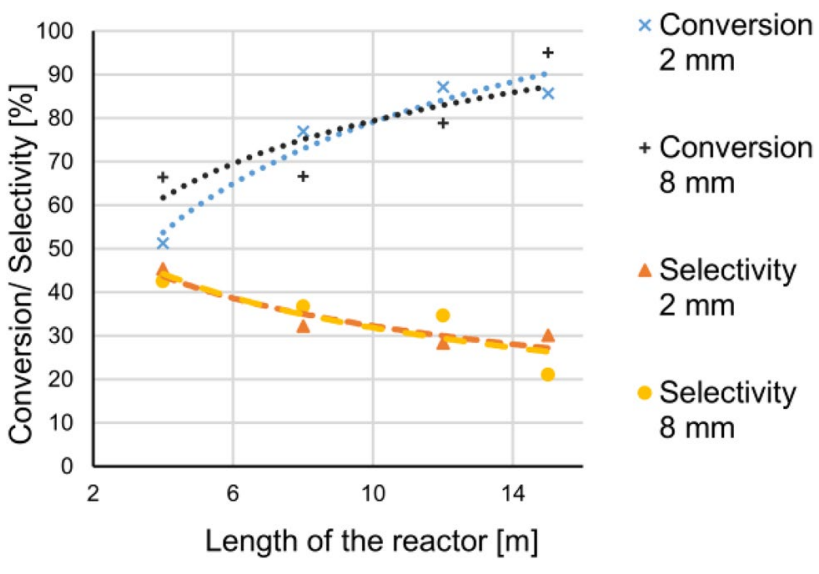

Fig. 15 Length vs Conversion \& Selectivity plot with trend for variation in slug length. Phase ratio $-7\left(\mathrm{~F}_{\mathrm{org}} / \mathrm{F}_{\mathrm{aq}}\right)$; Total Volumetric flowrate $-0.8 \mathrm{ml} / \mathrm{min}$ [organic-1,2 $\mathrm{ml} / \mathrm{min}$; aqueous $-0,4 \mathrm{ml} / \mathrm{min}$ ]; Slug length a) $2 \mathrm{~mm}$; b) $8 \mathrm{~mm}$

rate of $0.8 \mathrm{ml} / \mathrm{min}$, and different slug lengths of $2 \mathrm{~mm}$ and $8 \mathrm{~mm}$. A higher selectivity of epoxide is observed for $2 \mathrm{~mm}$ slug length in comparison to slug length of $8 \mathrm{~mm}$. It shows that a selectivity of $40 \%$ of epoxide is achieved at a reactor length of $4 \mathrm{~m}$ for a $2 \mathrm{~mm}$ slug length and the percentage of selectivity decreases along the length of the reactor. Lower selectivity of epoxide is reported for slug size of $8 \mathrm{~mm}$ in comparison to $2 \mathrm{~mm}$ slugs. Figure 15 shows similar effects of slug length on conversion for a different phase ratio of 7 and a volumetric flow rate of $0.8 \mathrm{ml} / \mathrm{min}$. Selectivities along the reactor are nearly identical for both slug lengths at this setting, indicating that the increase in phase ratio may render any effects of changes in slug length insignificant (Tables 6 and 7).

Figure 13 and the subsequent description explains the possible impacts of slug length on the reaction. The increased internal circulation facilitates the mass transfer across the film, resulting in a higher, faster conversion of MO. However, since the change in slug length only affects mixing within the aqueous slug, it likely does not affect the subsequent reactions of epoxide disproportionately, meaning selectivity is not impacted significantly. This trend can also be observed in systems, where the increased inter-slug and slug sizes lead to increased conversion of MO.

Figure 15 also illustrate that a larger aqueous slug, which acts as a reservoir of $\mathrm{H}_{2} \mathrm{O}_{2}$ molecules, combined with the

Table 6 Apparent rate constants of MO epoxidation and average observed selectivity for different total flow rates. Total flow rate $0.8 \mathrm{ml} / \mathrm{min}$, phase ratio 3

\begin{tabular}{lll}
\hline Slug length in $\mathrm{mm}$ & $\mathrm{k}_{\text {app }}$ in $\mathrm{min}^{-1}$ & $\begin{array}{l}\text { Average Selec- } \\
\text { tivity Epoxide } \\
\text { in \% }\end{array}$ \\
\hline 2 & 0.174 & 27.6 \\
8 & 0.181 & 26.3 \\
\hline
\end{tabular}


Table 7 Apparent rate constants of MO epoxidation and average observed selectivity for different total flow rates. Total flow rate $0.8 \mathrm{ml} / \mathrm{min}$, phase ratio 7

\begin{tabular}{lll}
\hline Slug length in $\mathrm{mm}$ & $\mathrm{k}_{\text {app }}$ in $\mathrm{min}^{-1}$ & $\begin{array}{l}\text { Average Selec- } \\
\text { tivity Epoxide } \\
\text { in } \%\end{array}$ \\
\hline 2 & 0.175 & 34.0 \\
8 & 0.179 & 33.4 \\
\hline
\end{tabular}

controlled mass transfer of the oxidant to the organic phase with the help of catalyst and the PTC, shows an effect similar to continuous addition in the batch system.

On the contrary, Fig. 16 shows that for a higher total flow rate, slug length is much more important for both conversion as well as selectivity, with a larger slug length yielding a much higher reaction rate and lower selectivity. As discussed previously, an increase in flow rate increases the overall reaction rate for both slug lengths. In contrast with the expectation to see higher reaction rates with an increase in specific area, the addition of surface area leads to a worse result (Table 8).

As Ufer et al. show using various imaging methods, the initially assumed, ideal mixing behaviour may not hold up in all cases. Considering these observations (illustrated in Fig. 17), it becomes apparent that changing of the slug lengths may affect

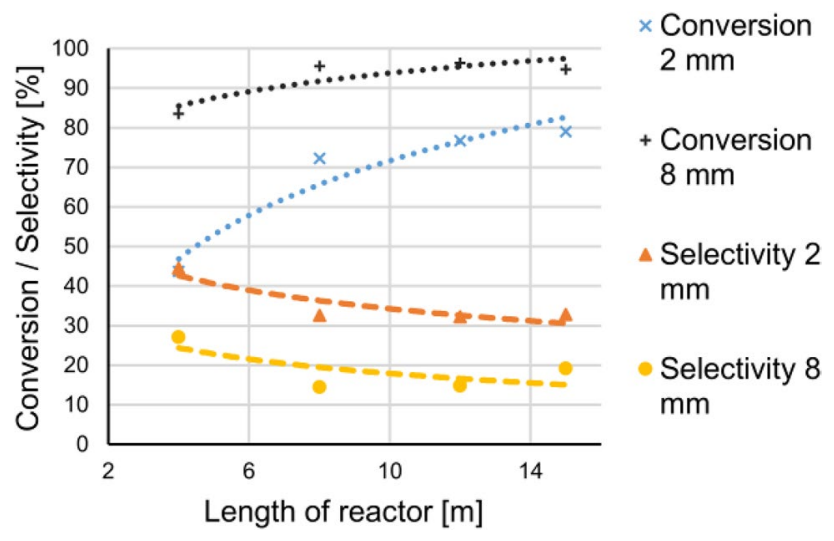

Fig. 16 Length vs Conversion \& Selectivity plot with trend for variation in slug length. Phase ratio $-3\left(\mathrm{~F}_{\text {org }} / \mathrm{F}_{\mathrm{aq}}\right)$; Total Volumetric flowrate $-1.6 \mathrm{ml} / \mathrm{min}$ [organic $-1.2 \mathrm{ml} / \mathrm{min}$; aqueous $-0.4 \mathrm{ml} / \mathrm{min}$ ]; Slug length a) $2 \mathrm{~mm}$; b) $8 \mathrm{~mm}$

Table 8 Apparent rate constants of MO epoxidation and average observed selectivity for different total flow rates. Total flow rate $1.6 \mathrm{ml} / \mathrm{min}$, phase ratio 3

\begin{tabular}{lll}
\hline Slug length in $\mathrm{mm}$ & $\begin{array}{l}\mathrm{k}_{\text {app }} \\
\text { in } \min ^{-1}\end{array}$ & $\begin{array}{l}\text { Average Selec- } \\
\text { tivity Epoxide } \\
\text { in \% }\end{array}$ \\
\hline 2 & 0.229 & 35.6 \\
8 & 0.527 & 18.9 \\
\hline
\end{tabular}

reaction outcomes in non-trivial ways [15]. This could explain why the change in reaction rate is very small for a small flow rate, despite a much larger specific area of the system at shorter slug lengths, as parts of the interfacial area are close to stagnant zones within the slugs, not benefitting from the good mass transfer implications of the Taylor vortices as shown in Fig. 17. It is also possible that more of the wall film than initially assumed takes part in the mass transfer. This implies that the interfacial area changes relatively little with slug length as described above. Because the wall film thickness increases with the slug velocity, some of the rate increase upon increase of the flow rate may in fact stem from an increased participation of the wall film in mass transfer.

\section{Effect of change in Phase Ratio}

In this case, the volumetric phase ratio of the system is changed by keeping the slug length and total volumetric flow rate at a constant value. The advantage of this system is its ability to manipulate the number of $\mathrm{MO}$ and $\mathrm{H}_{2} \mathrm{O}_{2}$ molecules available for the reaction system, as explained in Fig. 13. Compared to the batch mode, where further products are obtained due to the continuous addition of $\mathrm{H}_{2} \mathrm{O}_{2}$ [24], an easier solution is found in the continuous system.

In Figs. 18 and 19, for a fixed flow rate of $0.8 \mathrm{ml} / \mathrm{min}$ and a slug length of $2 \mathrm{~mm}$ and $8 \mathrm{~mm}$, two-phase ratios are analysed. As can be seen from both the figures, smaller phase ratios, result in better conversion. Low phase ratios and small slugs, implies higher internal circulation, facilitating the transfer of peroxo anions ions to the interface. The reaction takes place in the organic phase and the transfer of peroxo anions is facilitated by the presence of quaternary ammonium cations in the PTC present in the organic phase. Since the number of moles of MO present for a phase ratio of 3 is less, the oxidation occurs early, and a higher conversion level is achieved at a relatively lower length. For a phase ratio of 7, the number of moles of $\mathrm{MO}$ to be oxidised is more. Therefore, the length of the reactor to achieve a certain value of conversion for a phase ratio of 7 is greater than for a phase ratio of 3 (Tables 9 and 10).

When the overall continuous reactor is considered, if the throughput of the reactor is considered, higher phase ratios in this case, actually mean a larger number of $\mathrm{MO}$ molecules taking part in the reaction. The availability of $\mathrm{H}_{2} \mathrm{O}_{2}$ molecules to the reaction system can also be controlled by this variable.

\section{Conclusion}

The work aimed to develop a homogeneous catalytic system to achieve high conversion of MO and selectivity of epoxide in biphasic flow mode and explore the possibility of using 
Fig. 17 Slug flow with irregular flow pattern and stagnant zones [15]

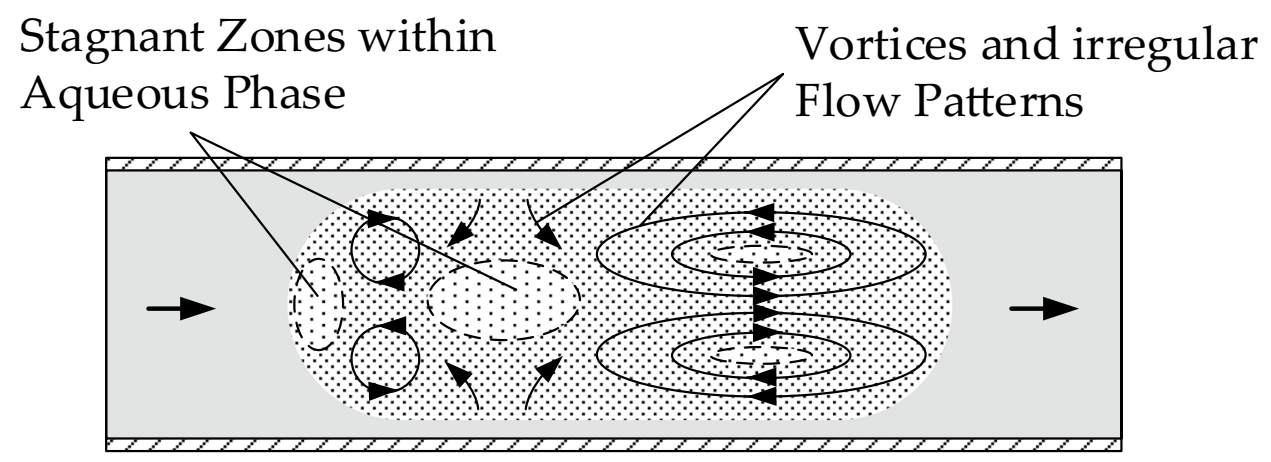

Aqueous Phase $\square$ Organic Phase

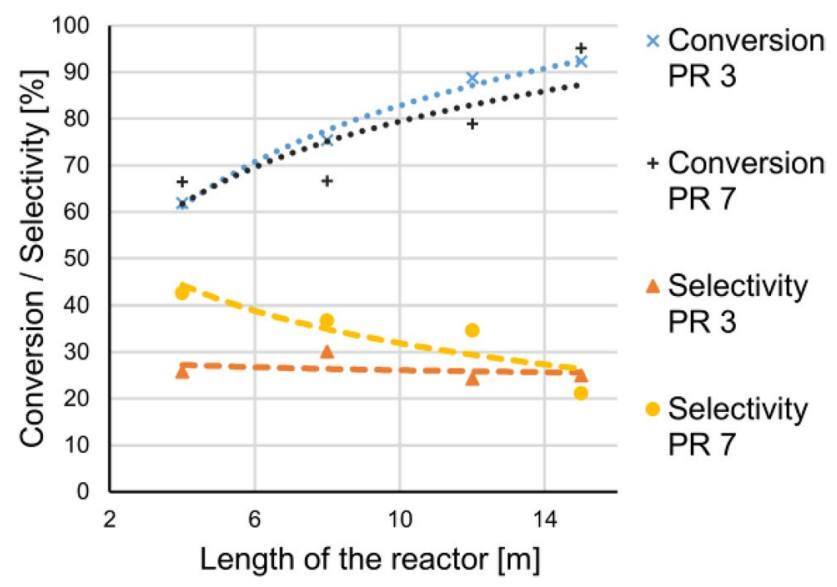

Fig. 18 Length vs Conversion \& Selectivity plot with trend for variation in phase ratio. Total Volumetric flowrate- $0,8 \mathrm{ml} / \mathrm{min}$; Slug length $-8 \mathrm{~mm}$; Phase ratio a) $3\left(\mathrm{~F}_{\text {org }} / \mathrm{F}_{\mathrm{aq}}=3 / 1\right)$ [organic flowrate$0,6 \mathrm{ml} / \mathrm{min}$; aqueous flow rate $-0,2 \mathrm{ml} / \mathrm{min}]$; b) $7\left(\mathrm{~F}_{\text {org }} / \mathrm{F}_{\mathrm{aq}}=7 / 1\right)$ [organic flowrate- $0,7 \mathrm{ml} / \mathrm{min}$; aqueous flow rate $-0,1 \mathrm{ml} / \mathrm{min}$ ]

slug flow variables to control reaction parameters, keeping the reactant feed streams' concentrations constant. The catalytic system of $\mathrm{H}_{2} \mathrm{O}_{2} /$ TPA/Aliquat ${ }^{\circledR} 336$ is employed for the oxidation of MO. Compared to Phimsen, Yamada et al., higher values of conversion of MO are achieved at relatively low residence times for batch experiments with comparable selectivity of epoxide [34]. To identify the optimal values

Table 9 Apparent rate constants of MO epoxidation and average observed selectivity for different total flow rates. Total flow rate $0.8 \mathrm{ml} / \mathrm{min}$, slug length $8 \mathrm{~mm}$

\begin{tabular}{lll}
\hline Phase ratio & $\mathrm{k}_{\mathrm{app}}$ in $\mathrm{min}^{-1}$ & $\begin{array}{l}\text { Average Selec- } \\
\text { tivity Epoxide } \\
\text { in } \%\end{array}$ \\
\hline 3 & 0.181 & 26.3 \\
7 & 0.175 & 33.4 \\
\hline
\end{tabular}

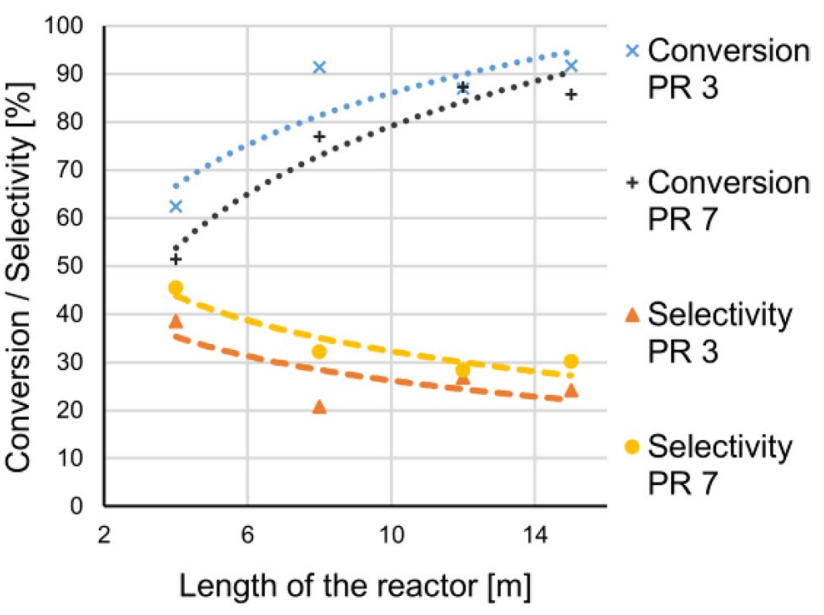

Fig. 19 Length vs Conversion plot with trend for variation in phase ratio. Total Volumetric flowrate- $0,8 \mathrm{ml} / \mathrm{min}$; Slug length $-2 \mathrm{~mm}$; Phase ratio a) $3\left(\mathrm{~F}_{\text {org }} / \mathrm{F}_{\mathrm{aq}}=3 / 1\right)$ [organic flowrate- $0,6 \mathrm{ml} / \mathrm{min}$; aqueous flow rate $-0,2 \mathrm{ml} / \mathrm{min}$ ]; b) $7\left(\mathrm{~F}_{\text {org }} / \mathrm{F}_{\mathrm{aq}}=7 / 1\right)$ [organic flowrate$0,7 \mathrm{ml} / \mathrm{min}$; aqueous flow rate $-0,1 \mathrm{ml} / \mathrm{min}$ ]

of the factors influencing conversion and selectivity, DoE is used. The linear and quadratic influences of the factors on conversion and selectivity are studied and a prediction of the responses is made using FCCC/design. The values of the predicted model from Modde 10.1 are comparable to the experimental results for batch experiments.

Table 10 Apparent rate constants of MO epoxidation and average observed selectivity for different total flow rates. Total flow rate $0.8 \mathrm{ml} / \mathrm{min}$, slug length $2 \mathrm{~mm}$

\begin{tabular}{lll}
\hline Phase ratio & $\mathrm{k}_{\text {app }}$ in $\min ^{-1}$ & $\begin{array}{l}\text { Average Selec- } \\
\text { tivity Epoxide } \\
\text { in \% }\end{array}$ \\
\hline 3 & 0.174 & 27.6 \\
7 & 0.179 & 34.0 \\
\hline
\end{tabular}


With the optimal values from batch experiments as a reference, the feed for the continuous system is prepared after considering the changes involved in calculating the material quantity ratios of flow variables. Experiments are performed to identify the effect of continuous mode parameters on the conversion and selectivity of the reaction system. The effect of the phase ratio of organic to the aqueous phase, the total volumetric flow rate of the reaction system, and the differences in the slug length are studied by changing one parameter for an experiment while the other two parameters are kept constant. The maximum length of the reactor used is $15 \mathrm{~m}$. A 3-way valve is placed at different lengths of the reactor, to obtain samples and to monitor the progress of the reaction. Samples are collected for analysis only after a steady state of flow is achieved. The phase ratio, total volumetric flow rate, and the pressure in the system are observed continuously. Experiments proved that each of the above-mentioned parameters influences the conversion and selectivity of the reaction system. Plots are constructed to understand the progress of the reaction along the length of the reactor. It is proven that high conversion of MO and desirable selectivity of epoxide is reached at lower residence time (10 $\mathrm{min})$ in comparison to the batch experiments $(3 \mathrm{~h})$.

The results suggest the possibility to control conversion and selectivity of the continuous reaction employing slug length, phase ratio, and total flowrate as actuating variables. However, the effects individual slug flow parameters have on the reaction outcome are not as clear and intuitive as initially assumed. Especially the trends observed for selectivity are difficult to explain simply with changes in interfacial area and internal mixing behaviour of the slug flows, remaining rather elusive. Considering the residence time of reactants in the reactor and the resulting system inertia, predictions about the system trajectory are likely necessary to control it effectively. Thus, a model of the slug flow reactor must be constructed. While physical (e.g. CFD) models of the slug flow regime have been constructed in the past [18] and their extension to include the reaction conducted in this work appears as a possibility, models for control purposes must be executable in real-time, limiting the possible complexity. Therefore, the creation of a data-based model using machine learning algorithms appears as a promising alternative capable of predicting the outputs of a system from a multitude of possible inputs, detached from the unclear physical basis.

\section{Appendix A-Experimental procedure for batch mode}

The procedure for the batch experiments are as follows: At first, $\mathrm{H} 2 \mathrm{O} 2$ is added to the system. The amount of $\mathrm{H} 2 \mathrm{O} 2$ required is calculated using the molar ratio of $\mathrm{H} 2 \mathrm{O} 2$ to $\mathrm{MO}$.
Then, Aliquat $₫ 336$ is loaded to the reaction medium followed by the addition of $1.5 \mathrm{~g}$ of MO. TPA is added to the system, therefore the catalytic complex synthesis is carried out in-situ. The experiments are carried out for different reaction times, stirrer speeds, and temperatures. The reaction is quenched in an ice bath after the reaction duration. Once the reaction is quenched, analysis of the aqueous and organic phases for selectivity and conversion determination is carried out with the help of Gas Chromatography.

\section{Appendix B - Working principle of DoE (Modde 10.1)}

The DoE proceeds stepwise. At first, screening of the factors takes place followed by the optimization objective. Screening of the factors is done at first to find those factors that influence both linear and interaction models. Linear models describe the influence of a single factor on the reaction system. If the linear model shows a value in the positive region of the plot, then the increase in the factor increases the responses given to a system. An interaction model explains the strength in the relation between an independent and dependent factor, as a function of other independent factors. After the screening of factors, the optimization mode is activated. The factors are entered as inputs with upper and lower limits.

\section{Appendix C-Comparison of the number of experiments between conventional design and FCCC design}

Table 11 Comparison of the number of experiments between conventional design and FCCC design

\begin{tabular}{lll}
\hline $\begin{array}{l}\text { Number of } \\
\text { Factors }\end{array}$ & $\begin{array}{l}\text { Number of experiments for } \\
\text { conventional design }\end{array}$ & $\begin{array}{l}\text { Number of experi- } \\
\text { ments for FCCC- } \\
\text { design }\end{array}$ \\
\hline 2 & 9 & 8 \\
3 & 27 & 14 \\
4 & 81 & 24 \\
5 & 243 & 26 \\
6 & 729 & 44 \\
7 & 2187 & 78 \\
\hline
\end{tabular}




\section{Appendix D - Batch DOE experiments \& results}

Table 12 Results of batch experiments

\begin{tabular}{|c|c|c|c|c|c|c|c|c|c|}
\hline Exp. No & Temperature $\left[{ }^{\circ} \mathrm{C}\right]$ & PTC:C [-] & MO:C [-] & $\mathrm{H} 2 \mathrm{O} 2 \mathrm{MO}[-]$ & Stirrer [RPM] & Time $[\mathrm{h}]$ & $\mathrm{X}_{\mathrm{MO}}[\%]$ & $\mathrm{S}_{\mathrm{Epo}}[\%]$ & $\mathrm{S}_{\text {Diol }}[\%]$ \\
\hline 1 & 50 & 6 & 50 & 1 & 100 & 1 & 42 & 35 & 16 \\
\hline 2 & 50 & 1 & 200 & 1 & 100 & 1 & 28 & 55 & 8 \\
\hline 3 & 50 & 6 & 50 & 4 & 100 & 1 & 38 & 34 & 17 \\
\hline 4 & 50 & 1 & 200 & 4 & 100 & 1 & 16 & 49 & 14 \\
\hline 5 & 50 & 1 & 50 & 1 & 600 & 1 & 8 & 23 & 21 \\
\hline 6 & 50 & 6 & 200 & 1 & 600 & 1 & 53 & 51 & 20 \\
\hline 7 & 50 & 1 & 50 & 4 & 600 & 1 & 35 & 48 & 16 \\
\hline 8 & 50 & 6 & 200 & 4 & 600 & 1 & 97 & 42 & 29 \\
\hline 9 & 80 & 1 & 50 & 1 & 100 & 1 & 19 & 51 & 23 \\
\hline 10 & 80 & 6 & 200 & 1 & 100 & 1 & 46 & 48 & 18 \\
\hline 11 & 80 & 1 & 50 & 4 & 100 & 1 & 34 & 64 & 24 \\
\hline 12 & 80 & 6 & 200 & 4 & 100 & 1 & 35 & 62 & 21 \\
\hline 13 & 80 & 6 & 50 & 1 & 600 & 1 & 50 & 31 & 18 \\
\hline 14 & 80 & 1 & 200 & 1 & 600 & 1 & 48 & 41 & 25 \\
\hline 15 & 80 & 6 & 50 & 4 & 600 & 1 & 89 & 36 & 26 \\
\hline 16 & 80 & 1 & 200 & 4 & 600 & 1 & 89 & 41 & 29 \\
\hline 17 & 50 & 1 & 50 & 1 & 100 & 5 & 37 & 15 & 16 \\
\hline 18 & 50 & 6 & 200 & 1 & 100 & 5 & 56 & 44 & 21 \\
\hline 19 & 50 & 1 & 50 & 4 & 100 & 5 & 60 & 16 & 6 \\
\hline 20 & 50 & 6 & 200 & 4 & 100 & 5 & 39 & 31 & 15 \\
\hline 21 & 80 & 6 & 50 & 1 & 100 & 5 & 49 & 27 & 14 \\
\hline 22 & 80 & 1 & 200 & 1 & 100 & 5 & 28 & 46 & 13 \\
\hline 23 & 80 & 6 & 50 & 4 & 100 & 5 & 76 & 33 & 18 \\
\hline 24 & 80 & 1 & 200 & 4 & 100 & 5 & 54 & 42 & 16 \\
\hline 25 & 65 & 1 & 125 & 2.5 & 350 & 3 & 85 & 40 & 26 \\
\hline 26 & 65 & 6 & 125 & 2.5 & 350 & 3 & 98 & 43 & 29 \\
\hline 27 & 65 & 3.5 & 50 & 2.5 & 350 & 3 & 92 & 43 & 27 \\
\hline 28 & 65 & 3.5 & 200 & 2.5 & 350 & 3 & 98 & 46 & 31 \\
\hline 29 & 65 & 3.5 & 125 & 1 & 350 & 3 & 56 & 53 & 21 \\
\hline 30 & 65 & 3.5 & 125 & 4 & 350 & 3 & 64 & 46 & 20 \\
\hline 31 & 65 & 3.5 & 125 & 2.5 & 350 & 1 & 57 & 50 & 22 \\
\hline 32 & 65 & 3.5 & 125 & 2.5 & 350 & 5 & 91 & 23 & 21 \\
\hline 33 & 65 & 3.5 & 125 & 2.5 & 350 & 3 & 94 & 34 & 23 \\
\hline 34 & 80 & 1 & 50 & 1 & 600 & 5 & 38 & 30 & 32 \\
\hline 35 & 50 & 6 & 50 & 1 & 600 & 5 & 61 & 40 & 20 \\
\hline 36 & 50 & 1 & 200 & 1 & 600 & 5 & 54 & 42 & 20 \\
\hline 37 & 80 & 6 & 200 & 1 & 600 & 5 & 53 & 58 & 23 \\
\hline 38 & 80 & 1 & 50 & 4 & 600 & 5 & 49 & 47 & 20 \\
\hline 39 & 50 & 6 & 50 & 4 & 600 & 5 & 99 & 16 & 21 \\
\hline 40 & 50 & 1 & 200 & 4 & 600 & 5 & 98 & 21 & 25 \\
\hline 41 & 80 & 6 & 200 & 4 & 600 & 5 & 98 & 31 & 25 \\
\hline 42 & 50 & 3.5 & 125 & 2.5 & 350 & 3 & 98 & 39 & 25 \\
\hline 43 & 80 & 3.5 & 125 & 2.5 & 350 & 3 & 95 & 34 & 21 \\
\hline 44 & 65 & 3.5 & 125 & 2.5 & 350 & 3 & 98 & 35 & 25 \\
\hline 45 & 65 & 3.5 & 125 & 2.5 & 350 & 3 & 90 & 39 & 24 \\
\hline 46 & 65 & 2.5 & 100 & 3 & 100 & 3 & 91 & 42 & 22 \\
\hline 47 & 65 & 2.5 & 600 & 3 & 600 & 3 & 98 & 39 & 24 \\
\hline
\end{tabular}


Fig. 20 DoE response contour for MO conversion at constant Temperature and MO:C ratio

Fig. 21 DoE response contour for selectivity toward epoxide at constant PTC:C and H2O2:MO ratios

\section{D Response Contour of Conversion}

Conversion

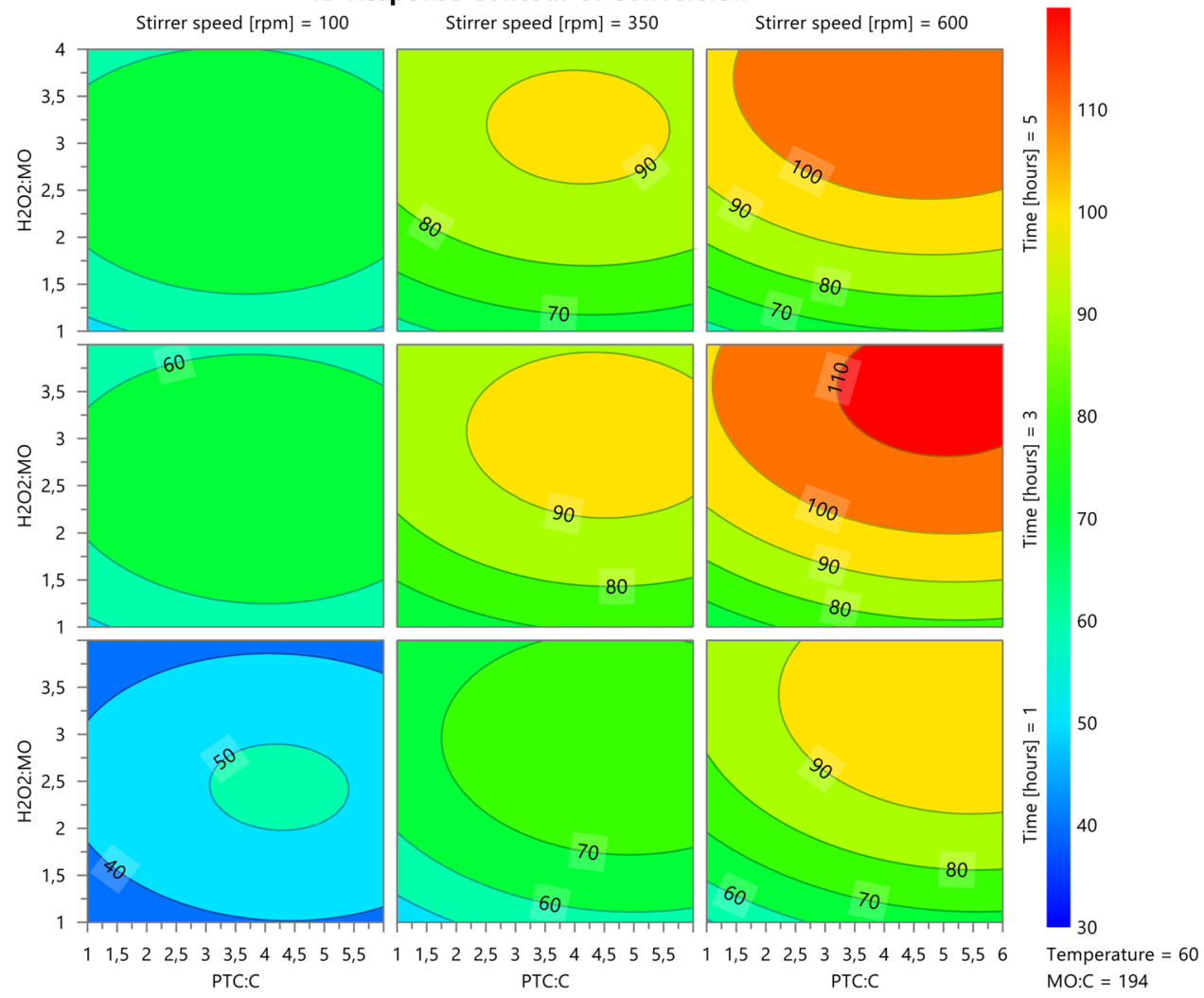

4D Response Contour of Selectivity toward Epoxide

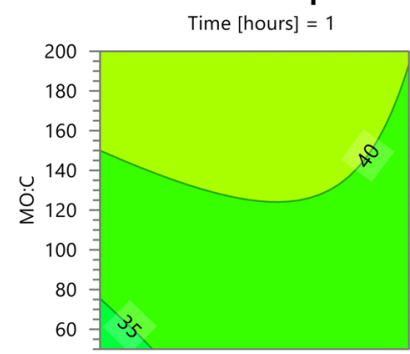

Time [hours] $=3$

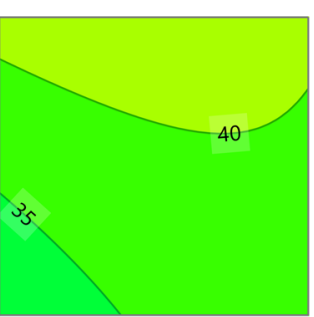

Time $[$ hours $]=5$
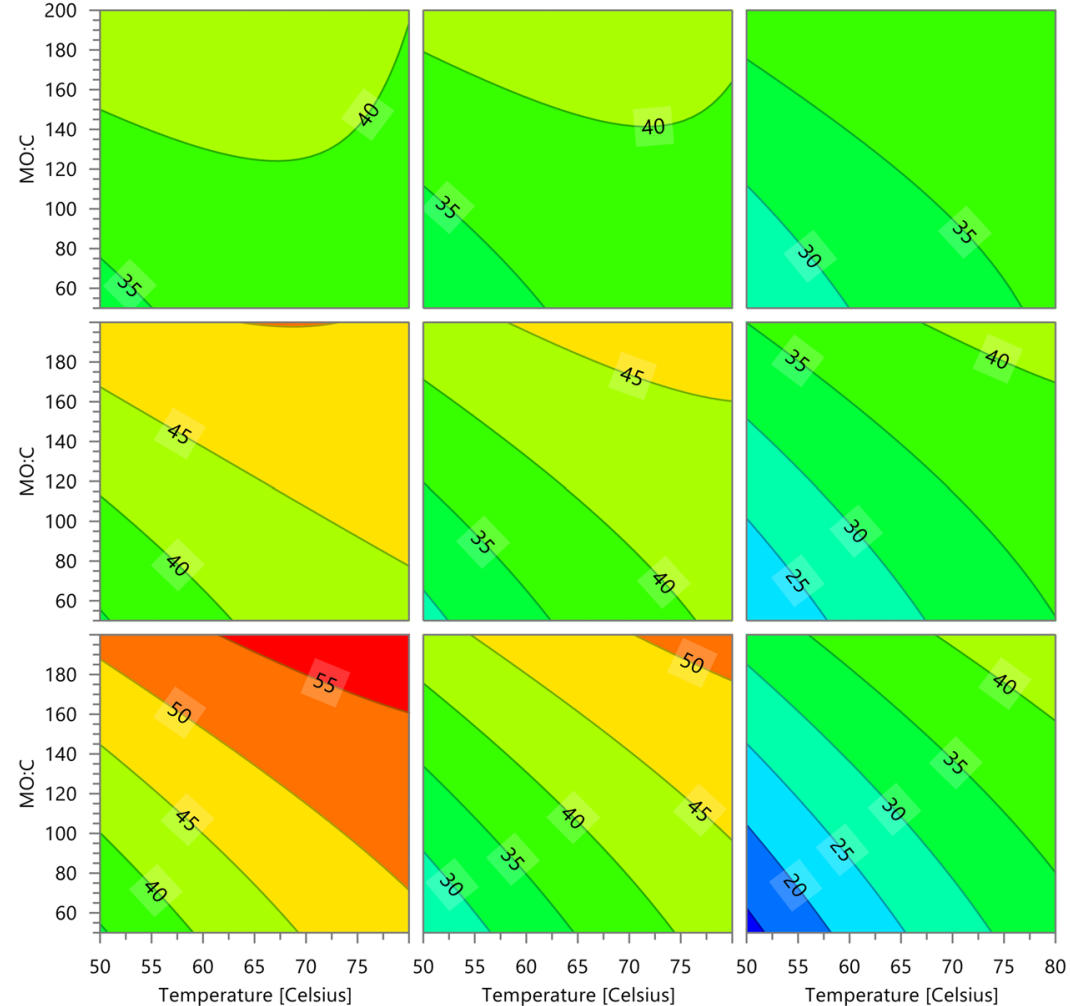

Temperature [Celsius]
Selectivity epoxide

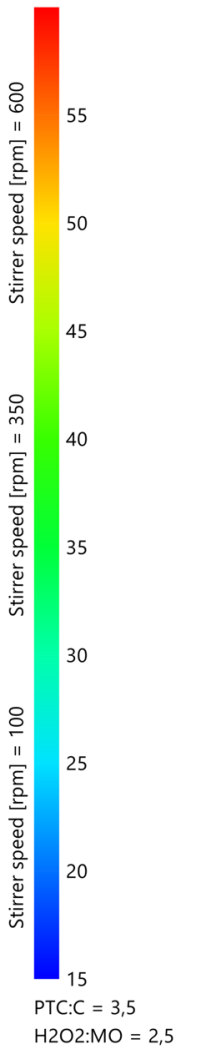


Table 13 DoE model parameters for conversion

\begin{tabular}{|c|c|c|c|c|}
\hline Conversion & Coeff. SC & Std. Err & $\mathrm{P}$ & Conf. int $( \pm)$ \\
\hline Constant & 92,732 & 369,441 & $4.95 \mathrm{E}-11$ & 773,258 \\
\hline Temperature & $0,489,048$ & 182,681 & $0,791,809$ & 38,236 \\
\hline PTC:C & 792,215 & 182,681 & $0,000,355,472$ & 38,236 \\
\hline $\mathrm{MO}: \mathrm{C}$ & 31,982 & 182,681 & $0,0,961,268$ & 38,236 \\
\hline $\mathrm{H} 2 \mathrm{O} 2: \mathrm{MO}$ & 910,941 & 182,681 & 8.19E-01 & 38,236 \\
\hline Stirrer speed & 931,581 & 182,681 & $6.37 \mathrm{E}+00$ & 38,236 \\
\hline Time & 632,379 & 182,681 & $0,00,261,295$ & 38,236 \\
\hline Temp*Temp & $-315,342$ & 593,677 & $0,601,458$ & 12,426 \\
\hline PTC:C*PTC:C & $-390,997$ & 593,677 & $0,518,053$ & 124,259 \\
\hline MO:C*MO:C & $-321,256$ & 593,677 & $0,594,707$ & 124,259 \\
\hline H:MO*H:MO & $-919,171$ & 593,677 & $0,138,053$ & 124,259 \\
\hline StiSp*StiSp & $-340,554$ & 593,677 & $0,572,943$ & 124,259 \\
\hline Time*Time & $-707,038$ & 593,677 & $0,248,341$ & 12,426 \\
\hline Temp*PTC:C & $0,00,040,674$ & 161,889 & 1 & 338,842 \\
\hline Temp*MO:C & $-0,0,937,288$ & 161,889 & $0,954,438$ & 338,842 \\
\hline Temp*H:MO & 150,789 & 161,889 & $0,363,314$ & 338,842 \\
\hline Temp*StiSp & $-0,659,374$ & 161,889 & $0,688,341$ & 338,842 \\
\hline Temp*Time & $-381,889$ & 161,889 & $0,0,291,867$ & 338,842 \\
\hline PTC:C*MO:C & $-4,055$ & 161,889 & $0,0,215,214$ & 338,842 \\
\hline PTC:C*H:MO & $-0,564,956$ & 161,889 & $0,730,945$ & 338,842 \\
\hline PTC:C*StiSp & 188,533 & 161,889 & $0,258,603$ & 338,842 \\
\hline PTC:C*Time & $-108,482$ & 161,889 & $0,510,857$ & 338,842 \\
\hline MO:C*H:MO & $-0,564,905$ & 161,889 & $0,730,968$ & 338,842 \\
\hline MO:C*StiSp & 528,041 & 161,889 & $0,00,410,394$ & 338,842 \\
\hline MO:C*Time & $-174,437$ & 161,889 & $0,294,744$ & 338,842 \\
\hline H:MO*StiSp & 584,592 & 161,889 & $0,001,861$ & 338,842 \\
\hline H:MO*Time & 155,648 & 161,889 & $0,348,405$ & 338,842 \\
\hline StiSp*Time & $-174,513$ & 161,889 & $0,294,539$ & 338,842 \\
\hline$N=47$ & $\mathrm{Q} 2=$ & 0,720 & Cond. no. $=$ & 10,35 \\
\hline $\mathrm{DF}=19$ & $\mathrm{R} 2=$ & 0,917 & $\mathrm{RSD}=$ & 12,39 \\
\hline \multirow[t]{2}{*}{ Comp. $=3$} & $\mathrm{R} 2 \mathrm{adj} .=$ & 0,799 & & \\
\hline & & & Conf. lev. = & 0,95 \\
\hline
\end{tabular}


Table 14 DoE model parameters for selectivity

\begin{tabular}{llrlc}
\hline Selectivity & Coeff. SC & Std. Err & P & Conf. int $( \pm)$ \\
Epoxide & & & & \\
\hline Constant & 409,174 & 241,487 & $6.34 \mathrm{E}-08$ & 505,443 \\
Temperature & 346,038 & 11,941 & $0,00,922,114$ & 249,931 \\
PTC:C & $-0,550,782$ & 11,941 & $0,649,854$ & 249,931 \\
MO:C & 432,015 & 11,941 & $0,0,018,322$ & 249,931 \\
H2O2:MO & $-126,586$ & 11,941 & $0,30,239$ & 249,931 \\
Stirrer speed & $-116,448$ & 11,941 & $0,341,716$ & 249,931 \\
Time & $-479,787$ & 11,941 & $0,000,735,357$ & 249,931 \\
Temp*Temp & $-100,679$ & 388,059 & $0,798,084$ & 812,226 \\
PTC:C*PTC:C & $-0,251,094$ & 388,059 & $0,949,086$ & 812,226 \\
MO:C*MO:C & $0,159,932$ & 388,059 & $0,967,553$ & 812,226 \\
H:MO*H:MO & 112,338 & 388,059 & $0,775,345$ & 812,226 \\
StiSp*StiSp & $-0,421,675$ & 388,059 & $0,914,608$ & 812,226 \\
Time*Time & $-0,975,931$ & 388,059 & $0,804,135$ & 812,226 \\
Temp*PTC:C & $-113,919$ & 105,819 & $0,295,164$ & 221,485 \\
Temp*MO:C & $-155,748$ & 105,819 & $0,157,438$ & 221,485 \\
Temp*H:MO & 188,005 & 105,819 & $0,0,916,397$ & 221,485 \\
Temp*StiSp & $-17,423$ & 105,819 & $0,116,104$ & 221,485 \\
Temp*Time & $0,96,106$ & 105,819 & $0,375,145$ & 221,485 \\
PTC:C*MO:C & 207,749 & 105,819 & $0,0,644,256$ & 221,485 \\
PTC:C*H:MO & $-211,448$ & 105,819 & $0,0,602,127$ & 221,485 \\
PTC:C*StiSp & 104,232 & 105,819 & $0,337,004$ & 221,485 \\
PTC:C*Time & 151,341 & 105,819 & $0,168,906$ & 221,485 \\
MO:C*H:MO & $-225,397$ & 105,819 & $0,0,464,605$ & 221,485 \\
MO:C*StiSp & $-124,305$ & 105,819 & $0,25,463$ & 221,485 \\
MO:C*Time & $0,259,327$ & 105,819 & $0,809,033$ & 221,485 \\
H:MO*StiSp & $-0,686,246$ & 105,819 & $0,524,419$ & 221,485 \\
H:MO*Time & $-216,534$ & 105,819 & $0,0,548,229$ & 221,485 \\
StiSp*Time & 239,822 & 105,819 & $0,0,353,001$ & 221,485 \\
N=47 & Q2= & 0,280 & Cond. no. $=$ & 10,35 \\
DF=19 & R2= & 0,802 & RSD= & 8,099 \\
Comp.=3 & R2 adj.= & 0,521 & & \\
\hline & & Conf. lev. & 0,95 \\
\hline & & & &
\end{tabular}

\section{Appendix E - Transfer of batch parameters to flow mode}

In the transition of parameters from batch operation to continuous operation, some of the terms must be adapted for their usage. For example, the progress of a chemical reaction in batch mode is a measure of the duration of the reaction. In continuous flow mode, the progress is determined in spatial terms, i.e., length of the reactor. One of the most important parameters in a chemical reaction is the residence time $(\tau)$. The residence time in the batch reactor corresponds to the reaction time. In continuous flow mode, the residence time is calculated as a ratio of the volume of the reactor $(\mathrm{V})$ and total volumetric flow rate ("V") of all components.
Besides, the volume flow of components must be included in the calculation of material quantity ratios in the reactor. A change in the ratio of the volume flow of feed affects the mass flow of the system. $200 \mathrm{~g}$ of $70 \% \mathrm{MO}$ is taken as the basis for continuous experiments. Therefore, the volume of the feed system is calculated as a function of the density of the individual component $(\rho)$.

Where $\mathrm{m}$ is the mass of the component under consideration. Based on the above equation, the volume of MO considered for continuous experiments is found to be $229 \mathrm{ml}$ $(0,47 \mathrm{~mol}) . \sim 1$ molar equivalent of $\mathrm{H} 2 \mathrm{O} 2$ is sufficient for epoxidation of MO through batch experiments, according to Table 2. The corresponding volume of $\mathrm{H} 2 \mathrm{O} 2$ required for epoxidation of MO is determined using Eq. 10. A phase ratio of 5 between the organic and aqueous phases, is required for the epoxidation of MO based on volume flow.

Due to the higher solubility levels of TPA in water [35], it is mixed with $35 \% \mathrm{H} 2 \mathrm{O} 2$ as an aqueous system. Aliquat ${ }^{\circledR}$ 336 , an organic compound, is soluble in systems containing a higher number of carbon atoms. Therefore, it is mixed with MO as the organic feed system. The amount of TPA and Aliquat ${ }^{\circledR} 336$ required to complete the feed system is calculated with the help of molar ratios of PTC/C and MO/C from Table 2 . The feed systems are continuously stirred to ensure proper mixing of the chemicals.

Acknowledgements The authors acknowledge the contribution of Jonas Mylenbusch in setting up the continuous flow reactor and total automation; Aboozar Nabi in experimenting with CPC as phase transfer catalyst in batch and flow mode; and Philipp Lapac in experimenting with the flow mode for homogenous system and helping develop LabView interface.

Author Contribution Anoj Winston Gladius: conceptualization, methodology, investigation, writing - original draft preparation, and visualization; Johanna Vondran: conceptualization, methodology, investigation, writing - review and editing, Yashwanth Ramesh: methodology, investigation, writing; Thomas Seidensticker: supervision-review and editing; David William Agar: supervision—review and editing.

Funding The authors acknowledge financial support by Deutsche Forschungsgemeinschaft and TU Dortmund University within the funding program Open Access Publishing. The financial support from Fonds der Chemischen Industrie is also gratefully acknowledged.

Open Access This article is licensed under a Creative Commons Attribution 4.0 International License, which permits use, sharing, adaptation, distribution and reproduction in any medium or format, as long as you give appropriate credit to the original author(s) and the source, provide a link to the Creative Commons licence, and indicate if changes were made. The images or other third party material in this article are included in the article's Creative Commons licence, unless indicated otherwise in a credit line to the material. If material is not included in the article's Creative Commons licence and your intended use is not permitted by statutory regulation or exceeds the permitted use, you will need to obtain permission directly from the copyright holder. To view a copy of this licence, visit http://creativecommons.org/licenses/by/4.0/. 


\section{References}

1. Enferadi Kerenkan A, Béland F, Do T-O (2016) Chemically catalyzed oxidative cleavage of unsaturated fatty acids and their derivatives into valuable products for industrial applications: a review and perspective. Catal Sci Technol 6:971-987. https://doi. org/10.1039/C5CY01118C

2. Hill K (2000) Fats and oils as oleochemical raw materials. Pure Appl Chem 72:1255-1264. https://doi.org/10.1351/pac2000720 71255

3. Sienel G, Rieth R, Rowbottom KT (2000) Epoxides. Ullmann's Encyclopedia of Industrial Chemistry. Wiley-VCH Verlag GmbH \& Co. KGaA, Weinheim, p 3527306730

4. Lligadas G, Ronda JC, Galià M, Biermann U, Metzger JO (2006) Synthesis and characterization of polyurethanes from epoxidized methyl oleate based polyether polyols as renewable resources. J Polym. Sci. Part A: Polym. Chem 44:634-645. https://doi.org/10. 1002/pola.21201

5. Sustaita-Rodríguez A, Ramos-Sánchez VH, Camacho-Dávila AA, Zaragoza-Galán G, Espinoza-Hicks JC, Chávez-Flores D (2018) Lipase catalyzed epoxidation of fatty acid methyl esters derived from unsaturated vegetable oils in absence of carboxylic acid. Chem Cent J 12:39. https://doi.org/10.1186/s13065-018-0409-2

6. Campos-Martin JM, Blanco-Brieva G, Fierro JLG (2006) Hydrogen peroxide synthesis: an outlook beyond the anthraquinone process. Angew Chem Int Ed Engl 45:6962-6984. https://doi.org/10. 1002/anie. 200503779

7. Sheldon RA (2017) The E factor 25 years on: the rise of green chemistry and sustainability. Green Chem 19:18-43. https://doi. org/10.1039/C6GC02157C

8. Caron S, Dugger RW, Ruggeri SG, Ragan JA, Ripin DHB (2006) Large-scale oxidations in the pharmaceutical industry. Chem Rev 106:2943-2989. https://doi.org/10.1021/cr040679f

9. Wai PT, Jiang P, Shen Y, Zhang P, Gu Q, Leng Y (2019) Catalytic developments in the epoxidation of vegetable oils and the analysis methods of epoxidized products. RSC Adv 9:38119-38136. https://doi.org/10.1039/C9RA05943A

10. de Torres M, Jiménez-Osés G, Mayoral JA, Pires E, Blanco RM, Fernández O (2012) Evaluation of several catalytic systems for the epoxidation of methyl oleate using $\mathrm{H} 2 \mathrm{O} 2$ as oxidant. Catal Today 195:76-82. https://doi.org/10.1016/j.cattod.2012.05.005

11. Kozhevnikov IV, Mulder GP, Steverink-de Zoete MC, Oostwal MG (1998) Epoxidation of oleic acid catalyzed by peroxo phosphotungstate in a two-phase system. J Mol Catal A: Chem 134:223-228. https://doi.org/10.1016/S1381-1169(98)00039-9

12. Venturello C, D'Aloisio R (1988) Quaternary ammonium tetrakis(diperoxotungsto)phosphates(3-) as a n ew class of catalysts for efficient alkene epoxidation with hydrogen peroxide. $\mathbf{J}$ Org Chem 53:1553-1557

13. Wiederhold, Grass, Woldt, Boeck, Thiele, Köhle (2015) Phasetransfer reagent for the epoxidation of unsaturated fatty acid alkyl Esters, World Intellectual Property Organization, WO 2015/177011 A1

14. Kashid MN, Renken A, Kiwi-Minsker L (2014) Microstructured Devices for Chemical Processing. Wiley-VCH Verlag GmbH \& Co. KGaA, Weinheim (ISBN 9783527685226)

15. Ufer A, Mendorf M, Ghaini A, Agar DW (2011) Liquid/Liquid Slug Flow Capillary Microreactor. Chem Eng Technol 34:353360. https://doi.org/10.1002/ceat.201000334
16. Kashid MN, Agar DW (2007) Hydrodynamics of liquid-liquid slug flow capillary microreactor: Flow regimes, slug size and pressure drop. Chem Eng J 131:1-13. https://doi.org/10.1016/J.CEJ. 2006.11.020

17. Bico J, Quéré D (2000) Liquid trains in a tube. Europhys Lett 51:546-550. https://doi.org/10.1209/epl/i2000-00373-4

18. Kashid MN, Gerlach I, Goetz S, Franzke J, Acker JF, Platte F, Agar DW, Turek S (2005) Internal Circulation within the Liquid Slugs of a Liquid-Liquid Slug-Flow Capillary Microreactor. Ind Eng Chem Res 44:5003-5010. https://doi.org/10.1021/ie0490536

19. Dummann G, Quittmann U, Gröschel L, Agar DW, Wörz O, Morgenschweis K (2003) The capillary-microreactor: a new reactor concept for the intensification of heat and mass transfer in liquidliquid reactions. Catal Today 79-80:433-439. https://doi.org/10. 1016/S0920-5861(03)00056-7

20. Arsenjuk L, Asshoff M, Kleinheider J, Agar DW (2020) A device for continuous and flexible adjustment of liquid-liquid slug size in micro-channels. J Flow Chem 10:409-422. https://doi.org/10. 1007/s41981-019-00064-7

21. Gaakeer WA, de Croon MHJM, van der Schaaf J, Schouten JC (2012) Liquid-liquid slug flow separation in a slit shaped micro device. Chem Eng J 207-208:440-444. https://doi.org/10.1016/j. cej.2012.06.148

22. Scheiff F, Mendorf M, Agar D, Reis N, Mackley M (2011) The separation of immiscible liquid slugs within plastic microchannels using a metallic hydrophilic sidestream. Lab Chip 11:1022-1029. https://doi.org/10.1039/C0LC00442A

23. Khlebnikova TB, Pai ZP, Fedoseeva LA, Mattsat YV (2009) Catalytic oxidation of fatty acids. II. Epoxidation and oxidative cleavage of unsaturated fatty acid esters containing additional functional groups. React Kinet Catal Lett 98:9-17. https://doi. org/10.1007/s11144-009-0054-9

24. Pai ZP, Tolstikov AG, Berdnikova PV, Kustova GN, Khlebnikova TB, Selivanova NV, Shangina AB, Kostrovskii VG (2005) Catalytic oxidation of olefins and alcohols with hydrogen peroxide in a two-phase system giving mono- and dicarboxylic acids. Russ Chem Bull 54:1847-1854. https://doi.org/10.1007/ s11172-006-0047-z

25. Godard A, de Caro P, Thiebaud-Roux S, Vedrenne E, Mouloungui Z (2013) New Environmentally Friendly Oxidative Scission of Oleic Acid into Azelaic Acid and Pelargonic Acid. J Am Oil Chem Soc 90:133-140. https://doi.org/10.1007/s11746-012-2134-7

26. Pai ZP, Yushchenko DY, Khlebnikova TB, Parmon VN (2015) $\mathrm{N}$-phosphonomethyl iminodiacetic acid $\mathrm{N}$-oxide synthesis in the presence of bifunctional catalysts based on tungsten complexes. Catal Commun 71:102-105. https://doi.org/10.1016/j.catcom. 2015.08.021

27. Karmoker JR, Hasan I, Ahmed N, Saifuddin M, Reza MS (2019) Development and Optimization of Acyclovir Loaded Mucoadhesive Microspheres by Box - Behnken Design. Dhaka Univ J Pharm Sci 18:1-12. https://doi.org/10.3329/dujps.v18i1.41421

28. Box GEP, Wilson KB (1992) On the Experimental Attainment of Optimum Conditions. In: Kotz S, Johnson NL (eds) Breakthroughs in Statistics. Springer New York, New York, pp 270-310 (ISBN 978-0-387-94039-7)

29. Arsenjuk L, von Vietinghoff N, Gladius AW, Agar DW (2020) Actively homogenizing fluid distribution and slug length of liquidliquid segmented flow in parallelized microchannels. Chemical Engineering and Processing - Process Intensification 156:108061. https://doi.org/10.1016/j.cep.2020.108061 
30. von Vietinghoff N, Lungrin W, Schulzke R, Tilly J, Agar DW (2020) Photoelectric Sensor for Fast and Low-Priced Determination of Bi- and Triphasic Segmented Slug Flow Parameters. Sensors (Basel) 20:6948. https://doi.org/10.3390/s20236948

31. Wang M-L, Huang T-H (2004) Kinetic Study of the Epoxidation of 1,7-Octadiene under Phase-Transfer-Catalysis Conditions. Ind Eng Chem Res 43:675-681. https://doi.org/10.1021/ie030253b

32. Wang M-L, Rajendran V (2007) Ultrasound assisted phasetransfer catalytic epoxidation of 1,7-octadiene - a kinetic study. Ultrason Sonochem 14:46-54. https://doi.org/10.1016/j.ultsonch. 2006.01.007

33. Wada Y, Schmidt MA, Jensen KF (2006) Flow Distribution and Ozonolysis in Gas-Liquid Multichannel Microreactors. Ind Eng Chem Res 45:8036-8042. https://doi.org/10.1021/ie060893p
34. Phimsen S, Yamada H, Tagawa T, Kiatkittipong W, Kiatkittipong K, Laosiripojana N, Assabumrungrat S (2017) Epoxidation of methyl oleate in a $\mathrm{TiO} 2$ coated-wall capillary microreactor. Chem Eng J 314:594-599. https://doi.org/10.1016/j.cej.2016.12.017

35. Holclajtner-Antunović I, Mioč UB, Todorović M, Jovanović Z, Davidović M, Bajuk-Bogdanović D, Laušević Z (2010) Characterization of potassium salts of 12-tungstophosphoric acid. Mater Res Bull 45:1679-1684. https://doi.org/10.1016/j.materresbull. 2010.06.064

Publisher's note Springer Nature remains neutral with regard to jurisdictional claims in published maps and institutional affiliations. 